Article

\title{
Biodegradable, Flame-Retardant, and Bio-Based Rigid Polyurethane/Polyisocyanurate Foams for Thermal Insulation Application
}

\author{
Marcin Borowicz ${ }^{1, *(\mathbb{D})}$, Joanna Paciorek-Sadowska ${ }^{1, *(\mathbb{D}}$, Jacek Lubczak ${ }^{2}$ and \\ Bogusław Czupryński ${ }^{1}$ \\ 1 Department of Chemistry and Technology of Polyurethanes, Institute of Materials Engineering, \\ Kazimierz Wielki University, J. K. Chodkiewicza Street 30, 85-064 Bydgoszcz, Poland; insttech@ukw.edu.pl \\ 2 Department of Organic Chemistry, Rzeszów University of Technology, Al. Powstańców Warszawy 6, \\ 35-959 Rzeszów, Poland; jml@prz.edu.pl \\ * Correspondence: m.borowicz@ukw.edu.pl (M.B.); sadowska@ukw.edu.pl (J.P.-S.); \\ Tel.: +48-34-19-286 (M.B.); +48-34-19-289 (J.P.-S.)
}

Received: 2 October 2019; Accepted: 3 November 2019; Published: 5 November 2019

\begin{abstract}
This article raised the issue of studies on the use of new bio-polyol based on white mustard seed oil and 2,2'-thiodiethanol (3-thiapentane-1,5-diol) for the synthesis of rigid polyurethane/polyisocyanurate (RPU/PIR) foams. For this purpose, new formulations of polyurethane materials were prepared. Formulations contained bio-polyol content from 0 to 0.4 chemical equivalents of hydroxyl groups. An industrial flame retardant, tri(2-chloro-1-methylethyl) phosphate (Antiblaze TCMP), was added to half of the formulations. Basic foaming process parameters and functional properties, such as apparent density, compressive strength, brittleness, absorbability and water absorption, aging resistance, thermal conductivity coefficient $\lambda$, structure of materials, and flammability were examined. The susceptibility of the foams to biodegradation in soil was also examined. The increase in the bio-polyol content caused a slight increase in processing times. Also, it was noted that the use of bio-polyol had a positive effect on the functional properties of obtained RPU/PIR foams. Foams modified by bio-polyol based on mustard seed oil showed lower apparent density, brittleness, compressive strength, and absorbability and water absorption, as well as thermal conductivity, compared to the reference (unmodified) foams. Furthermore, the obtained materials were more resistant to aging and more susceptible to biodegradation.
\end{abstract}

Keywords: mustard seed oil; rigid polyurethane/polyisocyanurate foam; bio-polyol; thermal insulation

\section{Introduction}

The economic doctrine of sustainable development keeps the balance between the economy, care for the environment, and quality of life. The fundamental principle of sustainable development is achieving the status that all basic human needs are met while maintaining the integrity of the Earth's ecosystem [1,2]. When it comes to polyurethane (PU) plastics, sustainable development mostly concerns two scopes. The first is the replacement of components derived from nonrenewable sources with their renewable counterparts. This main aim is a limiting of the extraction and processing of fossil raw materials and the reduction of the environmental degradation caused by this process. In turn, the second aim refers to the reduction of nondegradable waste emissions to the environment. It is possible, e.g., by introducing formulations into the ingredients which degrade in biotic and abiotic conditions [3]. This approach prevents depositing post-consumer waste in landfills or their thermal utilization, which is accompanied by the emission of environmentally toxic gases, such as hydrogen cyanide [4]. 
The most popular method of implementing the concept of sustainable development in the polyurethane industry is the use of components based on natural origin raw materials (e.g., bio-polyols or bio-fillers) for their production [5-9].

Research on the use of soybean oil-based bio-polyols was conducted by Miao et al. Authors used soy-polyols for the production of different kinds of polyurethane materials. On the basis of this bio-polyol, PU elastomer composites were obtained and characterized by very good mechanical properties and high cellular biocompatibility. The last parameter had particular importance in biomedical applications, e.g., in the implant production. The second bio-polyol was used to obtain foams with the so-called "shape memory". The research results proved that the use of soybean-based bio-polyols improved the properties and opened up new direction for applications for this material [10-12]. Veronese et al. used a mixture of petrochemicals and soy-based polyols for the production of rigid polyurethane foams. The obtained materials had better mechanical properties than their counterparts, which were obtained from petrochemical raw materials [13]. Dhaliwal et al. obtained polyurethane foams containing a polyol based on soybean oil. It was noted that the soy-based polyol was a valuable raw material. It enabled the production of PU foams with apparent density and thermal insulation properties comparable to the control sample and much better dimensional stability [14]. They also tested polyurethane foam containing a soybean oil-based polyol for insulation and structural applications. It was found that PU foam obtained using soy-based polyol can replace conventional petroleum-based PU foam for thermal insulation. A number of formulations were developed with varying amounts of blowing agent and catalyst to optimize the mechanical and thermal properties of soy-based PU foams. Based on the obtained test results, it was noted that the foam modified with vegetable polyol showed more favorable strength characteristics and better thermal properties in comparison to foams based on petrochemical raw materials [15].

Rapeseed oil-based bio-polyol was used to obtain all types of polyurethane foams, as well as elastomers, adhesives, and coatings [16]. Kurańska et al. did research on the replacement of petrochemical polyol for a bio-polyol based on rapeseed oil. The studies regarded the production of rigid polyurethane and polyurethane-polyisocyanurate foams. The obtained materials had similar properties (such as thermal conductivity coefficient, water absorption, closed cell contents) as unmodified foams $[8,16]$. Malewska et al. tested the effect of various rapeseed oil-based polyols concerning the properties of flexible polyurethane foams. The raw materials differed from each other due to the chemical structure and the hydroxyl number because various glycols were used to open the oxirane rings. Research showed that $20 \%$ of rapeseed-based bio-polyols had a positive effect on functional properties, such as hardness and comfort factor $[17,18]$.

Palm oil-based polyol is a crucial bio-polyol raw material for the production of polyurethanes. Research on its application is conducted mainly in Asia-its largest producer (about $90 \%$ of world production) [7]. Badri et al. obtained a bio-polyol based on the transesterification process of glycerides contained in vegetable oils with diethanolamine. It was used, inter alia, for the synthesis of polyurethane foams. Materials based on it were characterized by very good thermal insulation properties, strong adhesion to various surfaces, low water absorption, and high resistance to many aggressive environmental factors, e.g., acids, alkalis, sea salt, or organic solvents [19,20]. The same bio-polyol was used by Su'ait et al. to produce a solid electrolyte (PU-LiI) photovoltaic cell. The chemical reactions which occur in the electrolyte-electrode system are the source of the electric current generated by the solar panel. Studies have shown chemical interactions between segmented polyurethane based on plant origin raw material and lithium ion. The obtained bio-composite had high electrical conductivity, which was a noteworthy alternative to conventional electrolytic systems [21]. Septevani et al. conducted research on the influence of palm oil-based polyesterol on the properties of rigid polyurethane foams. Bio-polyol was used at various weight ratios in a mixture with petrochemical polyetherol. Composites containing $30 \%$ by weight of palm-based polyesterol in the mixture of polyol components were characterized by better mechanical properties [5]. Adnan et al. used bio-polyol based on palm-olein for the synthesis of high-resilient (HR) polyurethane foams. The conducted research showed that the implementation 
of vegetable-based polyol up to $25 \mathrm{wt} . \%$ did not have any influence on properties of the obtained materials [22].

The main aim of this research was to examine the effect of bio-polyol based on mustard seed oil on the basic functional properties, flammability, and biodegradation of rigid polyurethane-polyisocyanurate foams, which were obtained as a result of partial replacement of petrochemical polyol by vegetable-based polyol. Furthermore, the effect of bio-polyol on the properties of materials was examined after the elimination of a commercial flame retardant containing chloroorganic phosphates. These compounds are considered harmful to the environment. Therefore, new solutions are sought to reduce or eliminate them from use in the polyurethane industry. The obtained results were also compared with the parameters of commercial polyurethane-polyisocyanurate foam used as industrial thermal insulation materials.

\section{Materials and Methods}

\subsection{Materials}

White mustard seed oil-based bio-polyol and 2,2'-thiodiethanol (3-thiapentane-1,5-diol) with hydroxyl number $\mathrm{HN}=291.83 \mathrm{mg} \mathrm{KOH} / \mathrm{g}$ (produced in accordance with Pat. PL-233221 in Department of Chemistry and Technology of Polyurethanes, Kazimierz Wielki University, Bydgoszcz, Poland [23,24]) was used in the mixture with petrochemical polyol Rokopol RF-551 (sorbitol oxyalkylation product; hydroxyl number $\mathrm{HN}=420 \mathrm{mg} \mathrm{KOH} / \mathrm{g}$; produced by ZCh PCC Rokita SA, Brzeg Dolny, Poland) for the synthesis of rigid polyurethane-polyisocyanurate (RPU/PIR) foams. The used bio-polyol was obtained from cold-pressed white mustard seed oil in two-step synthesis (epoxidation and ring-opening reactions) and was marked with the abbreviation PG1. The detailed description of the synthesis (step by step), based on the cited patent, was described in [24-26]. Detailed properties of this raw material are in [24]. The schematic chemical formula of the bio-polyol (based on nuclear magnetic resonance (NMR) spectroscopy analysis, Figures S1-S6) is shown in Figure 1.

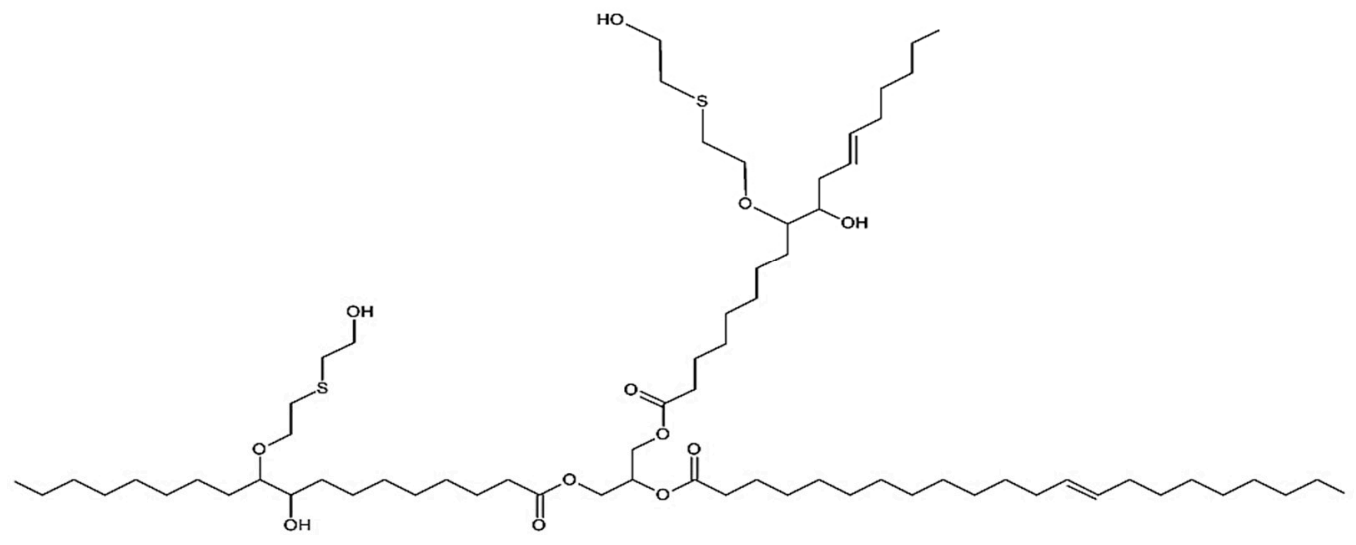

Figure 1. Schematic chemical structure of PG1 bio-polyol.

Purocyn B, a technical polyisocyanate (supplied by Purinova Ltd., Bydgoszcz, Poland), was used as the isocyanate raw material. The main component was 4,4'-diphenylmethane diisocyanate. The content of free NCO groups was equal to $31 \%$.

The catalytic system for synthesis of RPU/PIR foams was made from anhydrous potassium acetate (produced by Chempur, Piekary Ślaskie, Poland) used in a 33\% solution of diethylene glycol (produced by Chempur, Piekary Ślaskie, Poland). DABCO, a 1,4-diazabicyclo[2.2.2]octane (produced by Alfa Aesar, Haverhill, MA, USA), was also used in a 33\% solution of diethylene glycol. Tegostab 8460, a polysiloxanepolyoxyalkylene surfactant (produced by Evonik, Essen, Germany), was used as a foam structure stabilizer. Solkane HFC 365/227, a mixture of 1,1,1,3,3-pentafluorobutane and 1,1,1,2,3,3,3-heptafluoropropane in a mass ratio of 87:13 (produced by Solvay, Brussels, Belgium), 
was used as a blowing agent. Antiblaze TCMP, a tri(chloro-2-methylethyl) phosphate (produced by Albemarle, Charlotte, NC, USA), was used as a flame retardant.

\subsection{Preparation of RPU/PIR Foams}

The formulation of RPU/PIR foams with the addition of white mustard seed oil-based bio-polyol required experimental research to determine the optimal composition of additives (catalysts, surfactant, flame retardant, and blowing agent). The value of hydroxyl number was a base for the calculation of the polyol raw materials amount. The aforementioned value was used to calculate the quantities of polyols $[25,26]$. During the synthesis of foams, the petrochemical polyol was partially replaced by a mustard seed oil-based bio-polyol in an amount from 0 to 0.4 of chemical equivalent $(E q)$ of hydroxyl groups (every $0.1 \mathrm{Eq}$ ). The amount of isocyanate raw material was calculated regarding the chemical equivalent $(E q)$ ratio of the $\mathrm{NCO}$ to hydroxyl $(\mathrm{OH})$ groups in the reaction mixture, which was found to be 3:1 for RPU/PIR foams. The trimerization of the three NCO groups to the isocyanurate ring is necessary, as well as for the reaction between the $\mathrm{NCO}$ and $\mathrm{OH}$ groups to produce a urethane bond. The sum of the chemical equivalents of petrochemical polyol and mustard seed oil-based bio-polyol was always 1 . The amount of additives was determined, respectively, by the catalyst for the reaction between $\mathrm{NCO}$ and $\mathrm{OH}$ groups (1 wt. \%, the trimerization catalyst, $2.5 \mathrm{wt} . \%$, the physical blowing agent, $12 \mathrm{wt} . \%$, flame retardant, $17 \mathrm{wt} . \%$ and surfactant, and $1.7 \mathrm{wt} . \%$ in relation to the mass sum of polyols and polyisocyanate). Two series of foams modified with bio-based polyol were obtained-with commercial flame retardant (ZA) and without it (BA). The formulation of polyurethane-polyisocyanurate foams is shown in Table 1.

Table 1. Formulation of rigid polyurethane-polyisocyanurate (RPU/PIR) foams.

\begin{tabular}{|c|c|c|c|c|c|c|c|c|}
\hline $\begin{array}{l}\text { Foam } \\
\text { Symbol }\end{array}$ & $\begin{array}{c}\text { Rokopol } \\
\text { RF-551 } \\
\text { (Eq) } \\
\text { (g) }\end{array}$ & $\begin{array}{l}\text { PG1 } \\
(E q) \\
(\mathrm{g})\end{array}$ & $\begin{array}{c}\text { Tegostab } \\
8460 \\
\text { (g) }\end{array}$ & $\begin{array}{c}33 \% \\
\text { DABCO } \\
\text { (g) }\end{array}$ & $\begin{array}{l}33 \% \text { Potassium } \\
\text { Acetate } \\
\text { (g) }\end{array}$ & $\begin{array}{l}\text { Antiblaze } \\
\text { TCMP } \\
\text { (g) }\end{array}$ & $\begin{array}{c}\text { Solkane HFC } \\
365 / 227 \\
\text { (g) }\end{array}$ & $\begin{array}{l}\text { Purocyn B } \\
(E q) \\
(\mathrm{g})\end{array}$ \\
\hline P1.0 ZA & $\begin{array}{c}1.0 \\
66.80\end{array}$ & $\begin{array}{c}0.0 \\
0.00\end{array}$ & 4.59 & 2.70 & 6.75 & 45.90 & 32.40 & $\begin{array}{c}3.0 \\
203.2\end{array}$ \\
\hline P1.1 ZA & $\begin{array}{c}0.9 \\
60.12\end{array}$ & $\begin{array}{c}0.1 \\
9.59\end{array}$ & 4.60 & 2.71 & 6.77 & 46.04 & 32.75 & $\begin{array}{c}3.0 \\
203.2\end{array}$ \\
\hline P1.2 ZA & $\begin{array}{c}0.8 \\
53.44\end{array}$ & $\begin{array}{c}0.2 \\
19.18\end{array}$ & 4.62 & 2.71 & 6.79 & 46.19 & 33.10 & $\begin{array}{c}3.0 \\
203.2\end{array}$ \\
\hline P1.3 ZA & $\begin{array}{c}0.7 \\
46.76\end{array}$ & $\begin{array}{c}0.3 \\
28.78\end{array}$ & 4.63 & 2.72 & 6.81 & 46.34 & 33.45 & $\begin{array}{c}3.0 \\
203.2\end{array}$ \\
\hline P1.4 ZA & $\begin{array}{c}0.6 \\
40.08\end{array}$ & $\begin{array}{c}0.4 \\
38.37\end{array}$ & 4.64 & 2.73 & 6.84 & 46.48 & 33.80 & $\begin{array}{c}3.0 \\
203.2\end{array}$ \\
\hline P1.0 BA & $\begin{array}{c}1.0 \\
66.80\end{array}$ & $\begin{array}{c}0.0 \\
0.00\end{array}$ & 4.59 & 2.70 & 6.75 & 0.00 & 32.40 & $\begin{array}{c}3.0 \\
203.2\end{array}$ \\
\hline P1.1 BA & $\begin{array}{c}0.9 \\
60.12\end{array}$ & $\begin{array}{c}0.1 \\
9.59\end{array}$ & 4.60 & 2.71 & 6.77 & 0.00 & 32.75 & $\begin{array}{c}3.0 \\
203.2\end{array}$ \\
\hline P1.2 BA & $\begin{array}{c}0.8 \\
53.44\end{array}$ & $\begin{array}{c}0.2 \\
19.18\end{array}$ & 4.62 & 2.71 & 6.79 & 0.00 & 33.10 & $\begin{array}{c}3.0 \\
203.2\end{array}$ \\
\hline P1.3 BA & $\begin{array}{c}0.7 \\
46.76\end{array}$ & $\begin{array}{c}0.3 \\
28.78\end{array}$ & 4.63 & 2.72 & 6.81 & 0.00 & 33.45 & $\begin{array}{c}3.0 \\
203.2\end{array}$ \\
\hline P1.4 BA & $\begin{array}{c}0.6 \\
40.08\end{array}$ & $\begin{array}{c}0.4 \\
38.37\end{array}$ & 4.64 & 2.73 & 6.84 & 0.00 & 33.80 & $\begin{array}{c}3.0 \\
203.2\end{array}$ \\
\hline
\end{tabular}

The foams were obtained on a laboratory scale using the one-step method from the two-component (A and B) system. Component A was obtained from mixing appropriate amounts of polyols, catalysts, surfactant, blowing agent, and, optionally, flame retardant. Component B was a technical polyisocyanate, Purocyn B. The components A and B were mixed for $10 \mathrm{~s}$ with a mechanical stirrer $(1800 \mathrm{rpm})$ in a required mass ratio (Table 1$)$. Next, the mixture was poured into a rectangular open mold with internal dimensions of $25 \mathrm{~cm} \times 25 \mathrm{~cm} \times 30 \mathrm{~cm}$, where the free rising of foam took place. The progress of the foaming process was analyzed by an electronic stopwatch to determine the 
characteristic foaming times. Foams were thermostated for $4 \mathrm{~h}$ at $120^{\circ} \mathrm{C}$ in a laboratory dryer with forced circulation after removing from the mold.

\subsection{Characterization of RPU/PIR Foams}

The functional properties of obtained RPU/PIR foams were determined in accordance with the standards for rigid polyurethane foams.

\subsubsection{Processing Times}

Characteristic foaming time was analyzed during the process using an electronic stopwatch in accordance with ASTM D7487 13e $\mathrm{e}^{1}$. Cream, free-rise, string gel, and tack-free times were measured during synthesis of the RPU/PIR foams [27].

\subsubsection{Physico-Mechanical Properties}

The apparent density of foams (the ratio of foam weight to its geometrical volume) was determined for cube-shaped samples with a side length of $50 \mathrm{~mm}$ in accordance with ISO 845:2006.

The compressive strength was determined using the universal testing machine Instron 5544 (Instron, Norwood, MA, USA) in accordance with ISO 844:2014. The maximum force inducing a 10\% relative strain was determined (decreasing of the foam height in relation to the initial height, according to the direction of foam rise).

The brittleness of the foams was determined in accordance with ASTM C-421-08 as a percentage mass loss of 12 cubic foam samples with a side length of $25 \mathrm{~mm}$. Tests were conducted in a standard cuboidal box made of oak wood with dimensions of $190 \mathrm{~mm} \times 197 \mathrm{~mm} \times 197 \mathrm{~mm}$, rotating around the axis at a speed of $60 \mathrm{rpm}$. The filling of the box during the measurement were 24 normalized oak cubes with dimensions of $20 \mathrm{~mm} \times 20 \mathrm{~mm} \times 20 \mathrm{~mm}$. The brittleness (B) of obtained foams was calculated from Equation (1):

$$
B=\frac{m_{1}-m_{2}}{m_{1}} \cdot 100 \%
$$

where $m_{1}$-mass of the sample before test $(\mathrm{g})$ and $m_{2}$ —mass of the sample after test $(\mathrm{g})$.

Absorbability $(A)$ and water absorption (WA) were determined in accordance with ISO 2896:2001, which was measured after immersion in distilled water for $24 \mathrm{~h}$. Values of these parameters were calculated from Equations (2) and (3):

$$
A=\frac{m_{A}-m_{D}}{m_{D}} \cdot 100 \%
$$

where $m_{A}$-mass of the sample after immersion in distilled water $(\mathrm{g})$ and $m_{D}$-mass of the dry sample (g).

$$
W A=\frac{m_{W A}-m_{D}}{m_{D}} \cdot 100 \%
$$

where $m_{W A}-$ mass of the sample after surface drying $(\mathrm{g})$.

\subsubsection{Aging Resistance Properties}

Aging resistance of the foams was carried out in thermostating process of cubic samples with a side length of $50 \mathrm{~mm}$ for $48 \mathrm{~h}$ at a temperature of $120^{\circ} \mathrm{C}$. The result of this test included a change of linear dimensions $(\Delta l)$, change of geometrical volume $(\Delta V)$, and mass loss $(\Delta m)$. The values of these parameters were calculated in accordance with ISO 1923:1981 and PN-EN ISO 4590:2016-11. The formulas for the calculations of $\Delta l, \Delta V, \Delta m$ are shown in Equations (4)-(6).

$$
\Delta l=\frac{l-l_{0}}{l_{0}} \cdot 100 \%
$$


where $l_{0}$-length of the sample before thermostating (according to the direction of foam rise) ( $\mathrm{mm}$ ) and $l$-length of the sample after thermostating (according to the direction of foam rise) $(\mathrm{mm})$.

$$
\Delta V=\frac{V-V_{0}}{V_{0}} \cdot 100 \%
$$

where $V_{0}$-geometrical volume of the sample before thermostating $\left(\mathrm{mm}^{3}\right)$ and $V$-geometrical volume of the sample after thermostating $\left(\mathrm{mm}^{3}\right)$.

$$
\Delta m=\frac{m_{0}-m}{m_{0}} \cdot 100 \%
$$

where $m_{0}$-mass of the sample before thermostating $(\mathrm{g})$ and $m$-mass of the sample after thermostating $(\mathrm{g})$.

\subsubsection{Cell Structure}

The foam structure was analyzed by scanning electron microscope (SEM) HITACHI SU8010 (Hitachi High-Technologies Co., Tokyo, Japan). The studies were performed at the accelerating voltage of $30 \mathrm{kV}$, with the working distance of $10 \mathrm{~mm}$ and magnification of 150x. The statistical analysis of cell sizes, wall thickness, and content of cell per area unit was carried out on the basis of obtained micrographs using ImageJ software (LOCI, Madison, WI, USA).

\subsubsection{Thermal Insulation Properties}

Thermal conductivity of the foams was determined based on the determination of the thermal conductivity coefficient $\lambda$ in accordance with ISO 8301. Tests were carried out with the FOX 200 apparatus (TA Instruments, New Castle, DE, USA), in the measurement range of $\lambda$ equal to $20-100 \mathrm{~mW} /(\mathrm{m} \cdot \mathrm{K})$. Measurements were performed in the series at intervals of $0.5 \mathrm{~s}$ and at an average measuring temperature of $10{ }^{\circ} \mathrm{C}$ (temperature of hot plate $-20^{\circ} \mathrm{C}$, temperature of cold plate $-0{ }^{\circ} \mathrm{C}$ ).

The content of closed cells was determined in accordance with PN-EN ISO 4590:2016-11 using the helium pycnometer AccuPyc 1340 with the FoamPyc (Micrometrics, Norcross, GA, USA). This software calculated the content of closed cells based on the measurement of pressure changes in the test chamber.

\subsubsection{Flammability Tests}

The flammability of RPU/PIR foams was determined using four flammability tests: Bütler's combustion test (vertical test) in accordance with ASTM D3014-04, the horizontal combustion test in accordance with PN-EN ISO 3582:2002/A1:2008, limiting oxygen index in accordance with ISO 4589, and microcalorimeter pyrolysis combustion flow calorimeter (PCFC) in accordance with ASTM D7309-2007.

Bütler's combustion test consisted of burning a foam sample with the dimensions of $150 \mathrm{~mm} \times 20 \mathrm{~mm} \times 20 \mathrm{~mm}$ in a vertical column (chimney) with dimensions of $300 \mathrm{~mm} \times 57 \mathrm{~mm}$ $\times 54 \mathrm{~mm}$. Combustion residue (CR) was calculated from Equation (7):

$$
C R=\frac{m_{b}}{m_{a}} \cdot 100 \%
$$

where $m_{a}$-mass of the sample before the burning test $(\mathrm{g})$ and $m_{b}$-mass of the sample after the burning test (g).

The horizontal burning test consisted of determining the susceptibility of foam to flame. The result of this test was an evaluation of material flammability (nonflammable, flammable, or self-extinguishing). The average burning rate in flame (BR) of the tested materials was also determined based on this test. This parameter was defined by an equation (8):

$$
B R=\frac{s}{t}
$$


where $s$ - the distance, which was passed by flame during measurement $(\mathrm{mm})$, and $t$-time from the beginning of the measurement to the self-extinguishing of the flame (s).

The limiting oxygen index (LOI) was measured using the Concept Equipment apparatus (Rustington, UK). The percentage limited concentration of oxygen was determined in the mixture consisting of oxygen and nitrogen, which was sufficient to sustain the burning of the sample. LOI was calculated according to the Equation (9).

$$
L O I=\frac{\left[O_{2}\right]}{\left[O_{2}\right]+\left[N_{2}\right]} \cdot 100 \%
$$

where $\left[\mathrm{O}_{2}\right]$-volumetric flow of oxygen at the limit concentration $\left(\mathrm{m}^{3} / \mathrm{h}\right)$ and $\left[\mathrm{N}_{2}\right]$ - olumetric flow of nitrogen at the limit concentration $\left(\mathrm{m}^{3} / \mathrm{h}\right)$.

The fourth flammability test was the pyrolysis of RPU/PIR foams using a PCFC microcalorimeter (Fire Testing Technology, East Grinstead, UK). A microcalorimeter is a device designed to determine the rate of heat release (HRR) by materials. The test method is based on measuring heat and oxygen depletion during the thermal decomposition of a small sample of material. The decomposition is carried out in an inert atmosphere in the temperature range of $150-750{ }^{\circ} \mathrm{C}$ with a heating rate of $1{ }^{\circ} \mathrm{C} / \mathrm{s}$. Then, the gases formed as a result of pyrolysis are oxidized in a high-temperature furnace at $900{ }^{\circ} \mathrm{C}$ for complete oxidation. Parameters, such as time to ignition (TTI), time to flameout (TTF), heat release rate (HRR), and total heat released (THR), were determined by this device.

\subsubsection{Susceptibility to Biodegradation}

The study of biodegradation process RPU/PIR foams modified by mustard seed oil-based bio-polyols was carried out in accordance with ISO 17556:2012 using the OxiTop Control S6 apparatus (WTW-Xylem, Rye Brook, NY, USA), which used a respirometric method to measure the oxygen demand necessary for aerobic biodegradation of polymeric materials in soil. The measurement of consumed oxygen was presented using the value of biochemical oxygen demand (BOD), which is the number of milligrams of captured oxygen per mass unit of tested polyurethane material.

The OxiTop Control S6 apparatus consisted of six glass bottles with a capacity of $510 \mathrm{~mL}$ equipped with rubber quivers and measuring heads, which were used to measure BOD. They allowed us to measure the pressure in the range of $500 \mathrm{hPa}$ to $1350 \mathrm{hPa}$ with an accuracy of $1 \%$ at a temperature of $5{ }^{\circ} \mathrm{C}$ to $50^{\circ} \mathrm{C}$. The apparatus also included the OC 110 controller (WTW-Xylem, Rye Brook, NY, USA), It was used for communication between the measuring heads, user, and the Achat OC computer software (WTW-Xylem, Rye Brook, NY, USA), which was used to interpret the obtained measurement results.

Sifted and dried garden soil with a high humus content and physicochemical parameters, such as humidity of 5\% (according to ISO 11274), $\mathrm{pH}$ of 6 (according to ISO 10390), and grain diameter below $2 \mathrm{~mm}$ (collected in Szczepanowo, Kuyavian-Pomeranian Voivodeship, Poland), was used as a biodegradation environment. The measurement was carried out in a system consisting of $200 \mathrm{mg}$ of tested foam, $200 \mathrm{~g}$ of soil, and $100 \mathrm{~g}$ of distilled water. The hermetic-closed system was placed in a laboratory incubator at $20{ }^{\circ} \mathrm{C} \pm 0.2{ }^{\circ} \mathrm{C}$ and thermostated at this temperature for 28 days. All tested samples were comparable in size, because the absolute degree of polymer degradation depends on the form and shape of the material [28].

The BOD for a single OxiTop Control S6 bottle was determined from Equation (10) taking into account the BOD of the tested system reduced by the BOD of the soil and concentration of the tested material in the soil.

$$
B O D_{S}=\frac{B O D_{x}-B O D_{g}}{c}
$$

where $\mathrm{S}$ - number of measurement days, $\mathrm{BOD}_{\mathrm{S}}$ - biochemical oxygen demand of the analyzed material within $\mathrm{S}$ days $(\mathrm{mg} / \mathrm{L}), \mathrm{BOD}_{\mathrm{x}}$ - biochemical oxygen demand of the measuring system (bottle with sample and soil) $(\mathrm{mg} / \mathrm{L}), \mathrm{BOD}_{\mathrm{g}}$-biochemical oxygen demand of soil without a sample $(\mathrm{mg} / \mathrm{L})$, and $\mathrm{c}$ - sample concentration in the tested system $(\mathrm{mg} / \mathrm{L})$. 
The degree of biodegradation of the polymeric material was determined based on Equation (11):

$$
D_{t}=\frac{B O D_{S}}{T O D} \cdot 100 \%
$$

where $\mathrm{D}_{\mathrm{t}}$-degree of polymer biodegradation (\%) and TOD—theoretical oxygen demand $(\mathrm{mg} / \mathrm{L})$. The theoretical oxygen demand for each system was calculated from Equation (12):

$$
T O D=\frac{16[2 c+0.5(h-c l-3 n)+3 s+2.5 p+2 f+0.5 k-o]}{m_{r}}
$$

where $\mathrm{c}, \mathrm{h}, \mathrm{p}, \mathrm{s}, \mathrm{n}, \mathrm{cl}, \mathrm{f}, \mathrm{k}, \mathrm{o}$ - mass shares of elements in the macromolecule of biodegradable material $(-)$ and $\mathrm{m}_{\mathrm{r}}-$ sample mass of biodegradable material (g).

\section{Results and Discussion}

\subsection{Foaming Process and Reactivity of Bio-Polyol}

Processing times were measured during the preparation of RPU/PIR foams to determine the effect of bio-polyol on foaming parameters, i.e., cream time-from the start of mixing components $\mathrm{A}$ and B until fine bubbles appeared; free-rise time-from the start of mixing components A and B until the foam stops expanding; string gel time-from the start of mixing components A and B until long strings of tacky material can be pulled away from foam surface when the surface is touched by a tongue depressor; tack-free time-from the start of mixing components A and B until the foam surface can be touched by a tongue depressor without sticking. All foams retained the assumed percentage of additive raw materials (Table 1) for easier interpretation of the obtained results. The results of measurements are shown in Table 2. In both cases, the foams featured a tendency to elongate. A clear increase in processing times was noted after the use of bio-polyol in presence of commercial flame retardant (ZA series). This effect implied that the mustard oil-based polyol had lower reactivity than the petrochemical polyol. This is consistent with literature reports on other bio-polyols, e.g., based on rapeseed, soybean, sunflower, or palm oil [29-31].

Table 2. Processing times of RPU/PIR foams based on bio-polyol.

\begin{tabular}{ccccc}
\hline Foam Symbol & Cream Time (s) & String Gel Time (s) & Tack-Free Time (s) & Free Rise Time (s) \\
\hline P1.0 ZA & 6 & 21 & 24 & 34 \\
P1.1 ZA & 7 & 22 & 25 & 37 \\
P1.2 ZA & 7 & 23 & 27 & 44 \\
P1.3 ZA & 9 & 24 & 29 & 46 \\
P1.4 ZA & 9 & 31 & 35 & 47 \\
P1.0 BA & 9 & 20 & 23 & 29 \\
P1.1 BA & 9 & 20 & 23 & 29 \\
P1.2 BA & 9 & 20 & 23 & 31 \\
P1.3 BA & 9 & 20 & 23 & 33 \\
P1.4 BA & 9 & 20 & 23 & 34 \\
\hline
\end{tabular}

In the case of BA series foams, changes were not observed in the cream, string gel, and tack-free times. However, the free-rise times were slightly longer, meaning that the lower reactivity of the bio-polyol did not significantly affect the rate of the foaming process, despite materials obtained without commercial flame retardant having higher viscosity than the polyol premixes (component A). The elimination of flame retardant from the polyurethane formulations did not extend the processing times, which remained at the level of the reference foam. 


\subsection{Physico-Mechanical Properties}

An important parameter determining the use RPU/PIR foams as a thermal insulation material is their apparent density. It indirectly influences other physical and mechanical properties, e.g., compressive strength or brittleness [32,33]. Increasing the content of mustard seed oil-based bio-polyol decreased the apparent density of ZA series foams by $20 \%$ for $0.4 \mathrm{Eq}$ and BA series foams by $30 \%$ in comparison with appropriate reference foams. The decrease in the degree of polymer macromolecule packing was caused the addition of a component, which contained long, linear chains, to the polyurethane (Figure 1). It proved that fatty acid residues were flexible segments with low cross-linking potential. This phenomenon also significantly affected the compressive strength of rigid foams [34-36]. This parameter decreased with the increasing content of bio-polyol by $25 \%$ for ZA series and $30 \%$ for BA series. The main reason for the decrease was the increasing content of flexible segments in the polyurethane matrix. The dependence between apparent density, compressive strength, and bio-polyol content is shown in Figure 2. Despite the high decrease in apparent density and compressive strength, the values of these parameters remained at a satisfactory level compared to the material offered commercially (compressive strength higher than $250 \mathrm{kPa}$ ) [37].

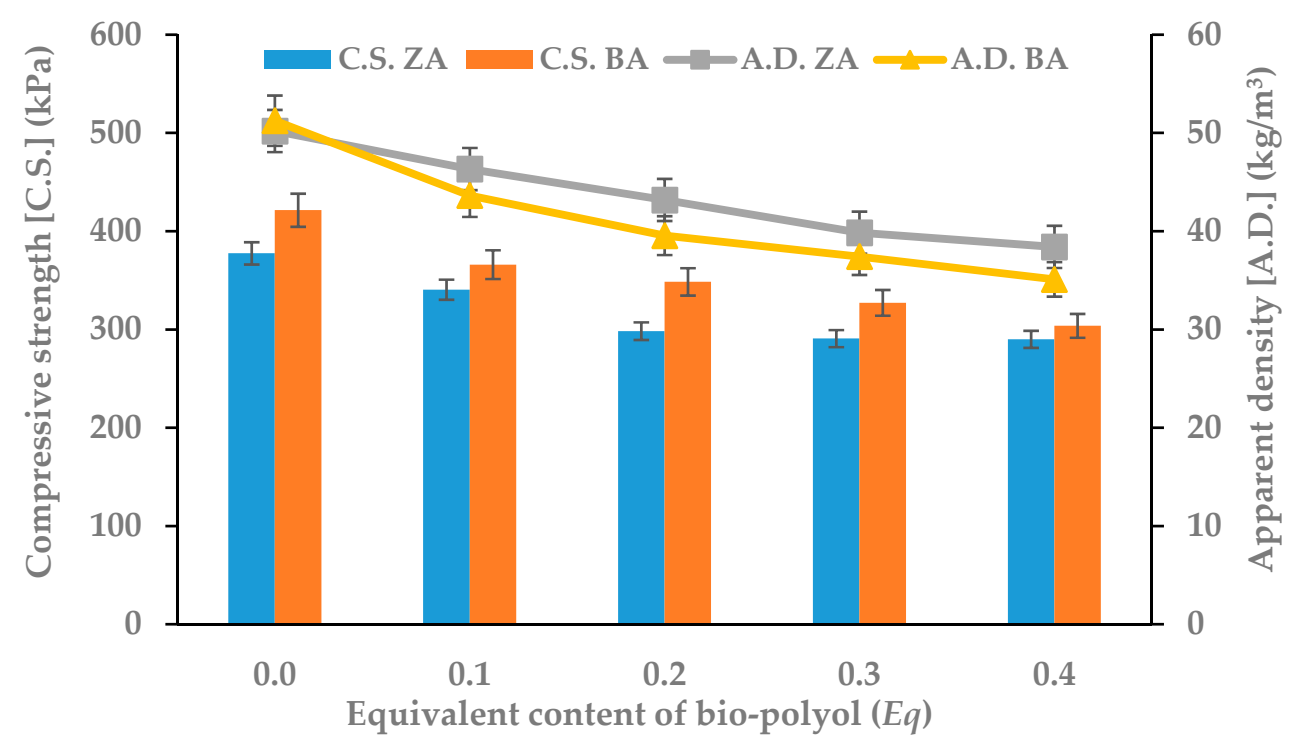

Figure 2. Dependence between bio-polyol content, compressive strength (C.S.) and apparent density (A.D.).

Another consequence of the decrease in the degree of polymer macromolecule packing was a slight decrease of stiffness and increase of flexibility, which led to a significant reduction in the brittleness of tge obtained rigid RPU/PIR foams. When a white mustard seed oil-based bio-polyol was used, the decrease of this parameter was more than $60 \%$ for the P1.4 ZA foam and 50\% for the P1.4 BA foam (Figure 3). The reduction of brittleness for the rigid polyurethane-polyisocyanurate foams meant an increase in resistance to mechanical factors and an increase in adhesion to various surfaces [38,39]. 


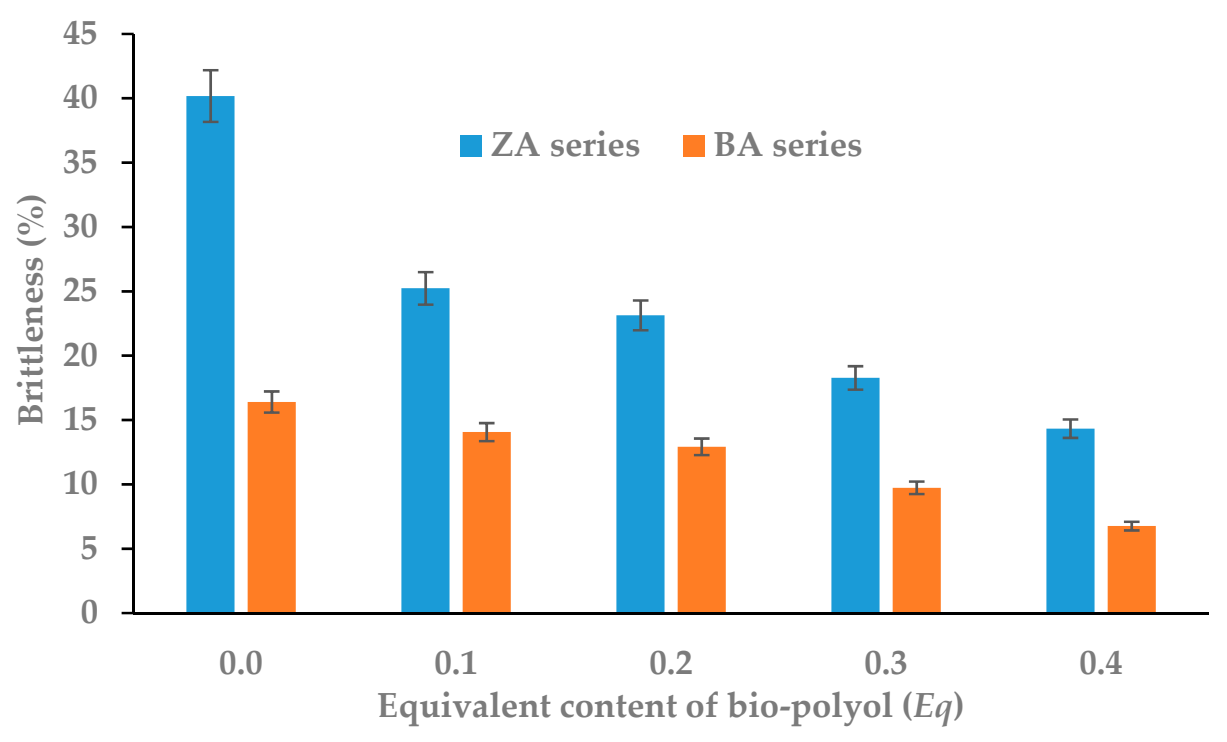

Figure 3. Dependence between bio-polyol content and brittleness of RPU/PIR foams.

An important parameter of porous thermal insulation materials is their absorbability and water absorption. The first parameter is the content of water in the material immediately after being taken out of the immersion (inside and on the foam surface). The second is a percentage value of water remaining inside the foam [40-42]. In both cases, a visible reduction in these parameters was noted (Figure 4). The decrease of absorbability and water absorption in foams based on bio-polyol was mainly caused by the addition of hydrophobic groups derived from vegetable oil into the polyurethane matrix. Moreover, the obtained results showed that the synthesized RPU/PIR foams met the requirements for commercially offered materials. The values of absorbability and water absorption allow them to be used as thermal insulating materials in high-humidity environments [43].

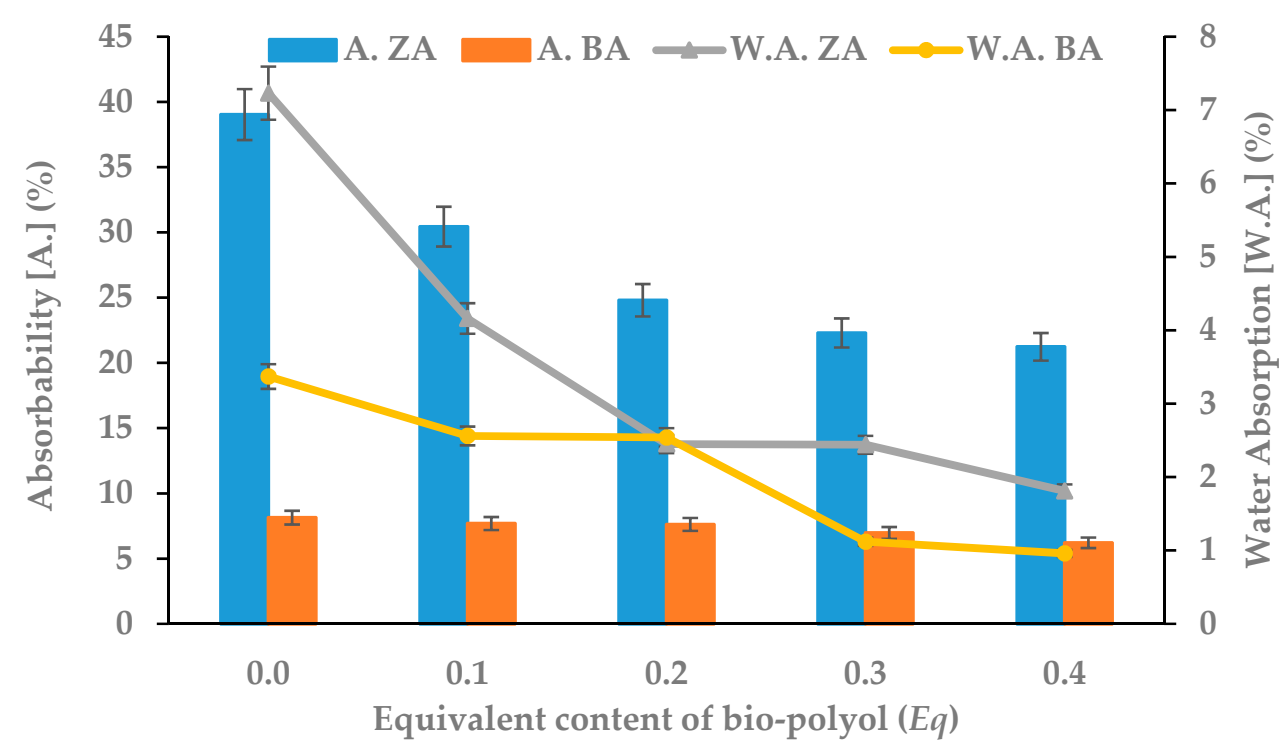

Figure 4. Dependence between bio-polyol content, absorbability (A.) and water absorption (W.A.).

Obtained results were in the range of values assumed for this type of polyurethane materials. Table 3 presents a comparison of foams with the highest content of white mustard oil-based bio-polyol with commercial RPU/PIR foam. 
Table 3. Physico-mechanical properties comparison of commercial RPU/PIR foam for thermal insulation and foams with $0.4 \mathrm{Eq}$ of bio-polyol content.

\begin{tabular}{cccc}
\hline Parameter & $\begin{array}{c}\text { Apparent Density } \\
\left(\mathbf{k g} / \mathbf{m}^{\mathbf{3}} \mathbf{)}\right.\end{array}$ & $\begin{array}{c}\text { Compressive Strength } \\
\mathbf{( k P a )}\end{array}$ & $\begin{array}{c}\text { Water Absorption after } \\
\mathbf{2 4} \mathbf{~ h} \mathbf{( \% )}\end{array}$ \\
\hline G40* & $36.0-42.0$ & $>250.00$ & $<3.00$ \\
P1.4 ZA & $38.4 \pm 1.1$ & $289.95 \pm 7.46$ & $1.81 \pm 0.06$ \\
P1.4 BA & $35.9 \pm 1.3$ & $303.67 \pm 5.32$ & $0.96 \pm 0.03$ \\
\hline \multicolumn{4}{r}{ * commercial RPU/PIR foam [37]. }
\end{tabular}

\subsection{Aging Resistance Properties of RPU/PIR Foams}

Aging resistance tests, i.e., stability of linear dimensions $(\Delta \mathrm{l})$ and change of geometrical volume $(\Delta \mathrm{V})$, showed that foams modified with bio-polyol up to $0.4 \mathrm{Eq}$ had these parameters at the same level as the reference foams, respectively, of $0.90 \%$ and $2.60 \%$ for the ZA series and $0.97 \%$ and $2.70 \%$ for the BA series. The increased content of long elastic segments allowed for an easier release of the blowing agent from foams (mixture of 1,1,1,3,3-pentafluorobutane and 1,1,1,2,3,3,3-heptafluoropropane - Solkane HFC 365/227) [44]. However, no changes were observed in the structure of the material indicating the increased diffusion of gases from the interior of the RPU/PIR foams.

Studies of mass loss after aging showed that the addition of the mustard oil-based bio-polyol caused the reduction of this parameter from $5.91 \%$ (ZA) and $2.88 \%$ (BA) for reference foams to $2.93 \%$ (ZA) and $1.25 \%$ (BA) for foams with 0.4 chemical equivalent of this raw material, meaning that the bio-polyol had a higher aging resistance than the petrochemical polyol because the oleochemical raw materials have better stability at higher temperature [45].

\subsection{Foam Structure}

In case of using plant-based polyols for the production of rigid polyurethane and polyurethane/polyisocyanurate foams, their influence on the shape and size of the cells of foam was noted. The use of mixtures of petrochemical polyol and soybean-based bio-polyol resulted in obtaining polyurethane materials with larger cell diameters than in materials without the participation of this bio-polyol [46]. On the other hand, using a bio-polyol based on castor oil and raw glycerol in a mixture with petrochemical polyol caused a beneficial influence on the cellular structure of RPU/PIR foams. There was a decrease in average cell diameter from $372 \mu \mathrm{m}$ to $275 \mu \mathrm{m}$ and an increase in the content of closed cells [47]. The cellular structure was examined for: reference foams, foams without mustard seed oil-based bio-polyol (P1.0 series ZA and BA), foams containing 0.1 chemical equivalent of the bio-polyol (P1.1), and foams with the highest content of the bio-polyol (P1.4). Based on micrographs presented on Figure 5, it was found that the increase in bio-polyol content caused an increase in cell diameters and a slight increase in wall thickness. The increase of bio-polyol content also caused a decrease in the symmetry of the cell structure. The average cell size, average wall thickness, and content of cells per volume unit were determined based on the SEM micrographs. The obtained results are showed in Table 4. 

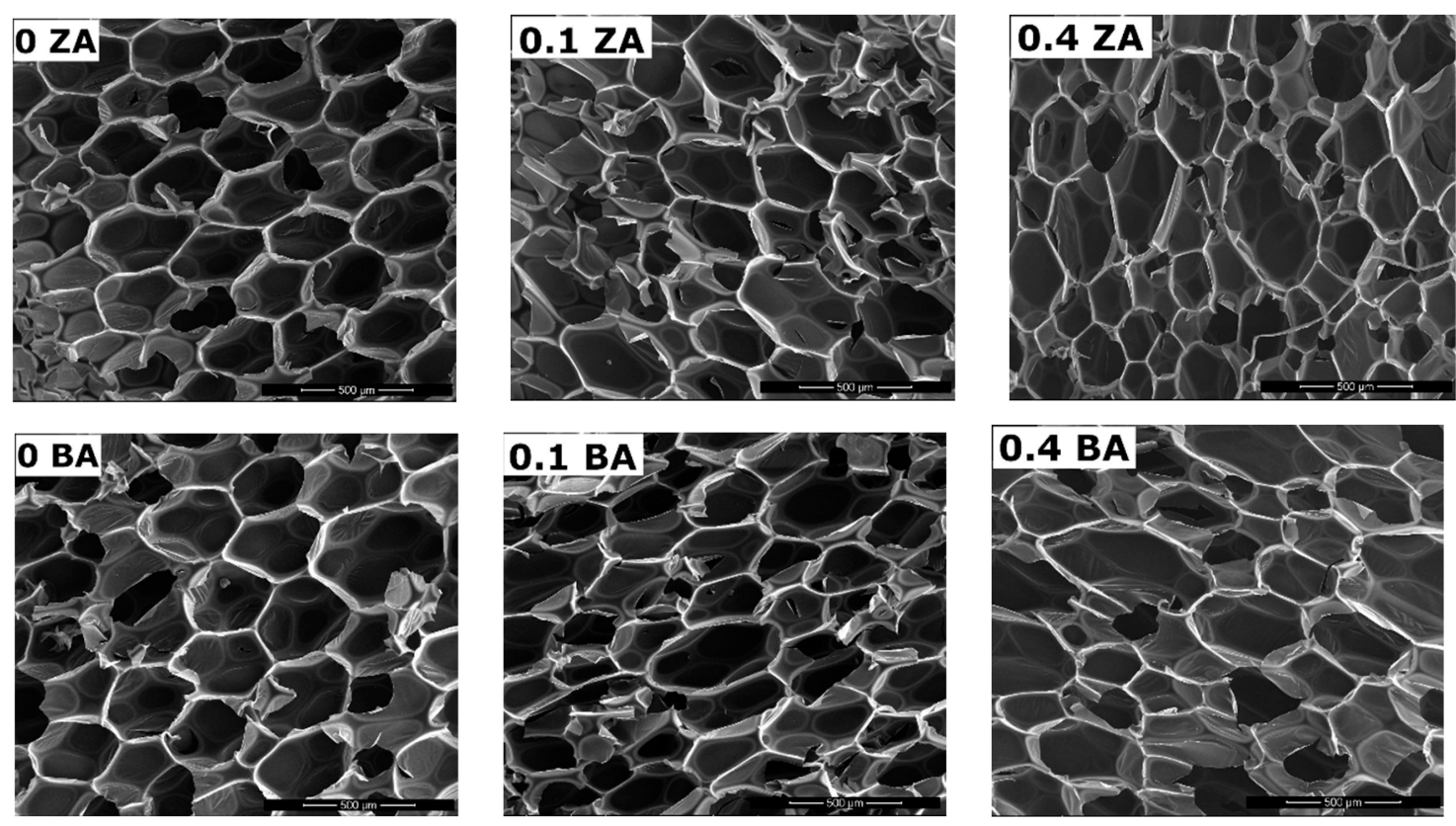

Figure 5. Micrographs of cellular structure of foam with 0, 0.1, and $0.4 \mathrm{Eq}$ of bio-polyol in 150x (ZA series on the top, BA series bottom).

Table 4. Results of SEM micrographs analysis.

\begin{tabular}{cccc}
\hline Foam Symbol & Cell Size $(\boldsymbol{\mu m})$ & $\begin{array}{c}\text { Thickness of Cell Wall } \\
(\boldsymbol{\mu m})\end{array}$ & $\begin{array}{c}\text { Content of Cells per } \\
\text { area unit }\left(\mathbf{c e l l s} / \mathbf{m m}^{\mathbf{2}}\right)\end{array}$ \\
\hline P1.0 ZA & $248 \pm 26$ & $18 \pm 2$ & $15 \pm 3$ \\
P1.1 ZA & $263 \pm 31$ & $22 \pm 2$ & $13 \pm 3$ \\
P1.4 ZA & $296 \pm 41$ & $27 \pm 3$ & $11 \pm 4$ \\
P1.0 BA & $273 \pm 34$ & $19 \pm 2$ & $13 \pm 2$ \\
P1.1 BA & $294 \pm 29$ & $22 \pm 3$ & $12 \pm 4$ \\
P1.4 BA & $317 \pm 43$ & $27 \pm 2$ & $11 \pm 4$ \\
\hline
\end{tabular}

The main factor that caused changes in foam structure was the addition of long linear molecules (fatty acid glycerides) of polyol. High flexibility of polyol segments and lower crosslinking (lower hydroxyl number than in commercial polyol) allowed greater migration of the blowing agent. As a result, the obtained foams had larger cell diameters and thicker walls. This was indirectly influenced by other RPU/PIR properties such as apparent density, compressive strength, and brittleness [48-50].

\subsection{Thermal Insulation Properties}

The most important parameter of the polyurethane materials dedicated for used as thermal insulation is $\lambda$, the thermal conductivity coefficient. If its value is lower, then the material is a better heat insulator [51]. With regard to foams obtained with the increasing content of bio-polyol, it was noted that the presence of a flame retardant had a significant effect on their thermal conductivity coefficient and insignificant effect on content of closed cells (Figure 6). 


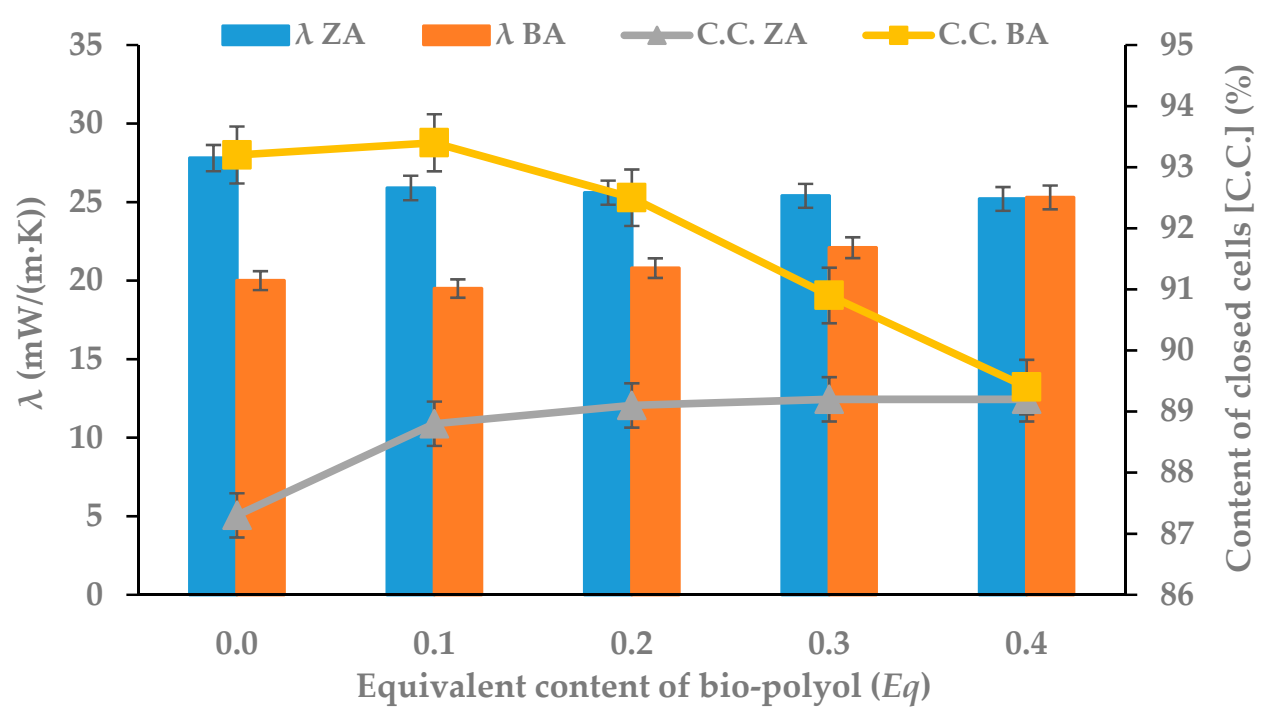

Figure 6. Dependence between bio-polyol content, thermal conductivity coefficient $\lambda$ and content of closed cells (C.C.).

The BA reference foam showed a 30\% lower coefficient $\lambda$ than the ZA reference foam. This was due to the more compact structure of the polyurethane matrix. Among the rigid PUR macromolecules were chemically unbound molecules of tri(2-chloro-1-methylethyl) phosphate, which disturbed the diffusion of heat during the measurement. The addition of molecules containing long partially bound aliphatic chains (fatty acid residues in bio-polyol) allowed for better diffusion of heat in the material. Hence, the noticeable increase of the $\lambda$ coefficient occurred in the BA foam series. The case of the ZA series was different. Alongside unbound molecules of flame retardant, there were also aliphatic chains which were partially connected with polyurethane matrix. Their mutual presence interfered with internal vibrations of molecules in polyurethane matrix, which caused a worse diffusion of heat through the material. Hence, a decrease in the value of this coefficient for ZA series was observed. In both cases, foams with the highest bio-polyol content had a lower $\lambda$ value than commercially heat insulation material, which was $0.028 \mathrm{~W} /(\mathrm{m} \cdot \mathrm{K})$ [37].

The content of closed cells in foams is as important as the thermal conductivity coefficient. An increase in the value of this parameter causes a decrease in the $\lambda$ value. It is known that the share of thermal conductivity of the gas contained in foam cells is about $60-80 \%$ of the total value of the thermal conductivity coefficient of polyurethane foam. The share of thermal conductivity depends primarily on the presence and type of blowing agent in the cells and the apparent density of the foam. The tendency to open cells and release blowing agent causes an increasing the thermal conductivity coefficient [52]. Based on the results presented in Figure 6, it can be seen that the content of closed cells increased from $87.3 \%(0 \mathrm{Eq})$ to $89.2 \%(0.4 \mathrm{Eq})$ for foams of the ZA series and decreased from $93.2 \%$ $(0 E q)$ to $89.4 \%(0.4 E q)$ for BA series foams. Changes in the value of this parameter are small enough to fall within the permissible industrial standards. Therefore, it can be concluded that the use of white mustard oil-based bio-polyol and a commercial flame retardant does not have a significant influence on the change of closed cell content in RPU/PIR foams.

\subsection{Flammability of RPU/PIR Foams}

The ease of ignition and release of large amounts of smoke during a fire, as well as the release of toxic gases, are significant difficulties associated with the use of polyurethanes. Increasing the flame retardancy of these materials is necessary to avoid safety issues and to comply with increasingly stringent legal requirements for flammability of plastics. Safety issues necessitate the use of thermally stable and nonflammable materials, which release little heat and toxic gases. Polyurethanes undergo thermal decomposition at high temperatures. High temperature, smoke, and volatile substances are 
produced at the beginning of the polyurethane combustion process. The last compounds consist of a mixture of flammable and nonflammable volatile substances such as monomers, hydrocarbons, carbon monoxide, and carbon dioxide. The actual quantity of produced volatile substances depends on the chemical structure and additive agents used in the polyurethane formulation. Flammable volatile substances react with oxygen to form of highly reactive hydrogen and hydroxide radicals, which accelerate further thermal decomposition and burning of polyurethane. Polyurethanes may degrade completely during thermal decomposition or may form charred or inorganic residues, depending primarily on the ingredients used in the formulation. The use of flame retardants can increase the time to ignition of polyurethane, reduce or eliminate the flame combustion phase, and reduce the heat release rate and flame propagation on the material surface [53].

The effect of flame-retardant compounds is usually considered from the point of view of reactions, which occur in the flame, and the formation of a boundary layer with different insulating properties. It is optimal to choose flame-retardant compounds that affect both of these phases (gas phase and condensed phase) [54]. A chemical modification based on the synergy effect of sulfur heteroatom with chlorine and phosphorus compounds was used as a part of this research. This modification consisted of the addition of these elements into the polyurethane foam matrix during their preparation.

The flammability tests of the obtained RPU/PIR foams were carried out by four methods: Determining the residue after combustion $(\mathrm{CR})$ in the vertical test, determining the limiting oxygen index (LOI), determining the material classification according to PN-EN ISO 3582:2002/A1:2008, and determining a fire parameters using PCFC calorimeter. These methods made it possible to compare the results of flammability of materials. This comparison was also possible after their modification using bio-polyol containing sulfur heteroatoms or the addition of a commercial flame retardant, Antiblaze TCMP. Changes in the values of combustion residue and limiting oxygen index of RPU/PIR foams with different content of white mustard oil-based bio-polyol oil and with or without flame retardant are presented in Figure 7.

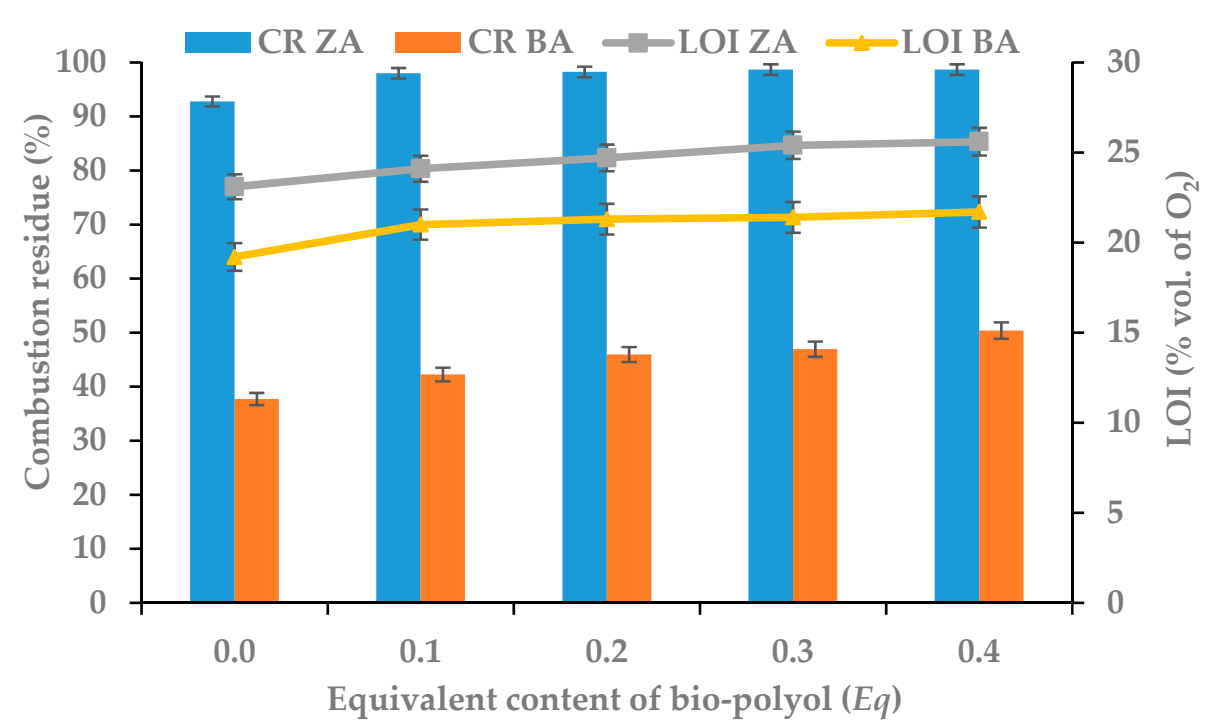

Figure 7. Dependence between bio-polyol content, combustion residue (CR) and limiting oxygen index (LOI).

Rigid polyurethane foams that do not contain flame retardants have a LOI value of up to $20 \%$. Therefore, they are flammable materials. The P1.0 BA reference foam, a foam obtained using only commercial polyol which did not contain a flame-retardant compound, had a LOI value of $19.2 \%$. Foams from P1.1 BA to P1.4 BA were obtained using plant-based polyol, which contained a sulfur heteroatom. The increasing content of this bio-polyol in the polyurethane formulation (increasing the percentage amount of sulfur) caused an increase in the LOI value to $21.7 \%$ for the foam with the highest 
content of it. However, the use of the flame-retardant compound in the formulation (ZA series of foams) resulted in a significant reduction of the flammability of obtained materials. This was confirmed by the results of the limiting oxygen index, which showed values increasing from $23.1 \%$ for the reference foam to $25.6 \%$ for the foam with the highest content of mustard-oil based bio-polyol containing sulfur heteroatoms. The obtained RPU/PIR foams modified with vegetable-based polyol and a flame-retardant compound showed significantly higher LOI values in the range of $21-26 \%$. These results classified them as slow-burning materials. It should be noted that the conducted research concerned the preparation of modified polyurethane/polyisocyanurate foams, which contained isocyanurate rings obtained by increasing the isocyanate index $[55,56]$. The presence of isocyanurate rings promoted the formation of a charred layer on the surface of the burning foam. This charred layer was formed from volatile flammable gases and acted as a protective barrier by sealing the polymer against oxygen and preventing the release of volatile products of polymer pyrolysis. Sulfur added into the polyurethane structure was transformed into sulfenic and thiosulfoxylic acids in the process oxidation of sulfide bonds. Then, it was gradually transformed into $\mathrm{SO}_{2}$ and $\mathrm{SO}_{3}$. These acids were the catalysts for ionic peroxide decomposition, while sulfur oxides inhibited chain reactions of oxidation. Thus, these compounds exerted a flame-retardant effect in the gas phase $[57,58]$, while the chloro-phosphorus organic compound had a flame-retardant effect in the condensed phase. The effectiveness of its operation consisted in creating a protective layer on the polymer surface hindering the spread of fire and heat transfer to further layers of the polymer. The flame-retardant compound was decomposed to simpler compounds that were involved in oxidation reaction by free radicals under the influence of heating. Then, there was a decrease in the concentration of active free radicals, which slowed down the combustion process [59-62]. The reason for the reduction of flammability of obtained RPU/PIR foams was the synergism of sulfur contained in the bio-polyol with chlorine and phosphorus contained in flame retardant (Antiblaze TCMP). Similar synergism was observed by Bhoyate et al. [63,64]. They confirmed the active flame-retardant effect in the combination of phosphorus containing compounds with natural raw materials such as soybean oil, castor oil, and limonene.

The limiting oxygen index results confirmed the values of combustion residue for the obtained RPU/PIR foams. Figure 7 shows a clear difference of this parameter for RPU/PIR foams containing bio-polyol and for reference foams. Materials based on bio-polyol were characterized by much higher combustion residues than unmodified foams. Even a small amount of this bio-polyol in the foam formulation significantly increased their CR (an increase of $6 \%$ for foam of ZA series and an increase of $13 \%$ foam of BA series). It is worth noting that the addition of a commercial flame-retardant compound contributed to a significant increase in the combustion residue for foams of the ZA series from $92.70 \%$ (P1.0) to $98.67 \%$ (P1.4) and for foams of the BA series from $37.72 \%$ (P1.0) to $50.39 \%$ (P1.4). Another reason for this phenomenon was the synergism of sulfur, chlorine, and phosphorus, which were components of flame retardant and bio-polyol incorporated into the polyurethane matrix.

The horizontal flammability test showed that all foams of the ZA series were self-extinguishing. In the case of foams of the BA series, the increase of bio-polyol content resulted in a change in material classification. The reference foam (P1.0 BA) was classified as a flammable material. In contrast, the foam with the highest content of bio-polyol was already self-extinguishing. The burning rate of material in flame (BR) was also determined based on this test. The results are shown in Figure 8, while appearance of foams after burning test is shown in Figure 9. 


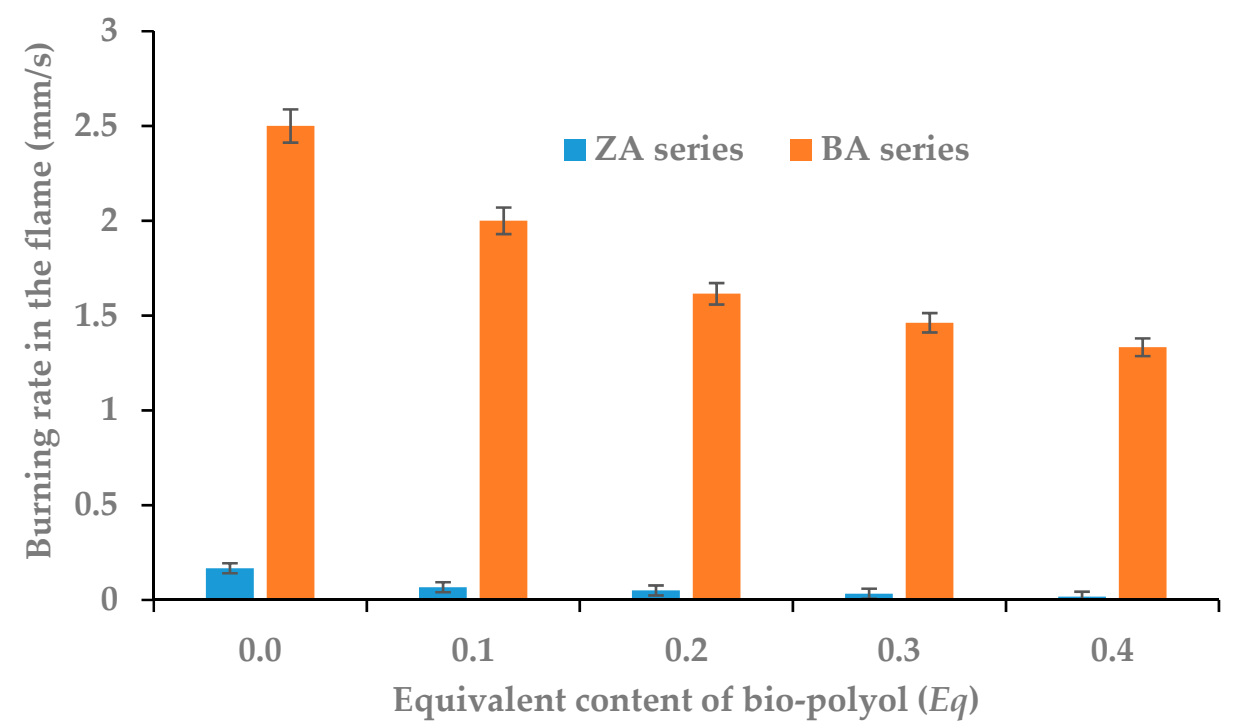

Figure 8. Dependence between bio-polyol content and burning rate in flame (BR).

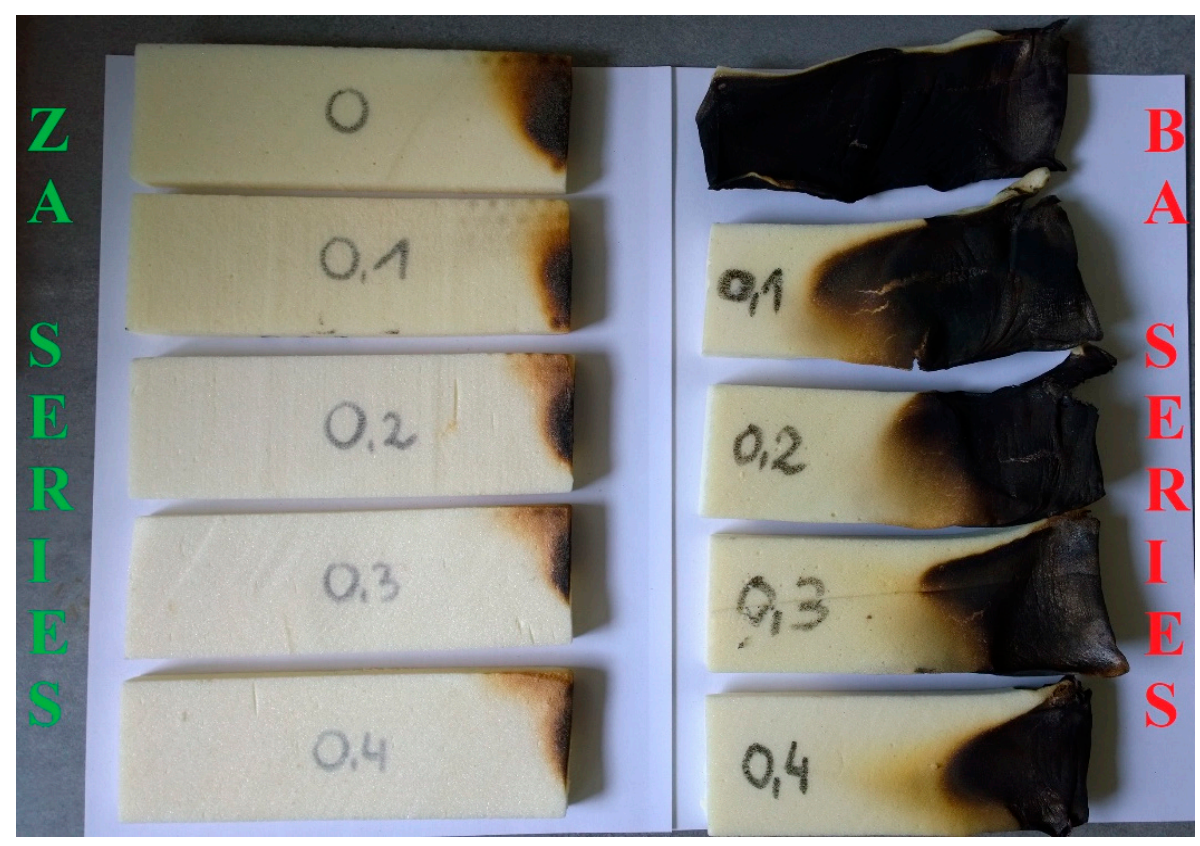

Figure 9. Appearance of ZA and BA series of foams after horizontal burning test.

The burning rate in the flame of the ZA series foams was low. However, the increase in bio-polyol content caused a 10-fold decrease of this parameter from $0.167 \mathrm{~mm} / \mathrm{s}$ to $0.017 \mathrm{~mm} / \mathrm{s}$, meaning that the P1.4 ZA foam practically did not burn. The burning rate in the flame of the BA series foams was much higher. This was obviously due to the lack of a commercial flame retardant. For the reference foam, the burning rate in the flame was $2.500 \mathrm{~mm} / \mathrm{s}$. The value of this parameter was almost half for foam with the highest content of mustard oil-based bio-polyol and 2,2'-thiodiethanol (P1.4 ZA), which was $1.330 \mathrm{~mm} / \mathrm{s}$. The obtained results confirmed the previously described effect of sulfur and flame retardant on flammability of RPU/PIR foams.

Significant information about flammability of RPU/PIR foams was provided by the PCFC microcalorimeter. However, it should be noted that the PCFC method used milligram quantities of polymer samples, and the analysis was carried out under specific conditions which do not reflect real fire conditions. Nevertheless, it is a commonly used method for the flammability assessment of various materials modified with flame retardants. These results are presented in Table 5. 
Table 5. Fire properties of selected RPU/PIR foams.

\begin{tabular}{|c|c|c|c|c|}
\hline Foam Symbol & TTI (s) & TTF (s) & HRR $\left(\mathrm{kW} / \mathrm{m}^{2}\right)$ & THR $\left(\mathrm{MJ} / \mathrm{m}^{2}\right)$ \\
\hline P1.0 ZA & $10 \pm 1$ & $128 \pm 2$ & $78.9 \pm 0.8$ & $16.9 \pm 0.5$ \\
\hline P1.4 ZA & $21 \pm 1$ & $69 \pm 2$ & $114.8 \pm 1.3$ & $9.7 \pm 0.3$ \\
\hline P1.0 BA & $6 \pm 1$ & $175 \pm 3$ & $69.4 \pm 0.7$ & $23.1 \pm 0.9$ \\
\hline P1.4 BA & $12 \pm 1$ & $125 \pm 1$ & $86.7 \pm 0.7$ & $15.6 \pm 0.3$ \\
\hline
\end{tabular}

One of the most important flame-retardancy parameters is the time to ignition (TTI) of the test sample. If this time is long, then the material will heat up longer and ignite longer. Then, the probability of fire is lower. Based on the obtained results, the P1.0 BA foam showed a very short ignition time (TTI $=6 \mathrm{~s}$ ), which is typical for materials with a porous structure (characterized by high flammability). The addition of flame-retardant compound in the P1.0 ZA foam formulation caused a slight increase of this time to $10 \mathrm{~s}$, while the RPU/PIR foams obtained on the basis of plant-based bio-polyol began to burn after $12 \mathrm{~s}$ and after $21 \mathrm{~s}$ for the P1.4 BA and the P1.4 ZA foams, respectively. It was easy to see that the addition of commercial flame retardant to the formulation containing bio-polyol increased the time to ignition more than two-fold. The time to flameout (TTF) was the longest for the P1.0 BA foam (175 s), while the heat was released slowly. On the other hand, the use of chloro-phosphorus flame retardant in a mixture with bio-polyol significantly reduced the time to flameout to $69.4 \mathrm{~s}$ for the P1.4 ZA foam. It also had an influence on the course of curves of heat release rate (HRR) of foams as a function of time (Figure 10).

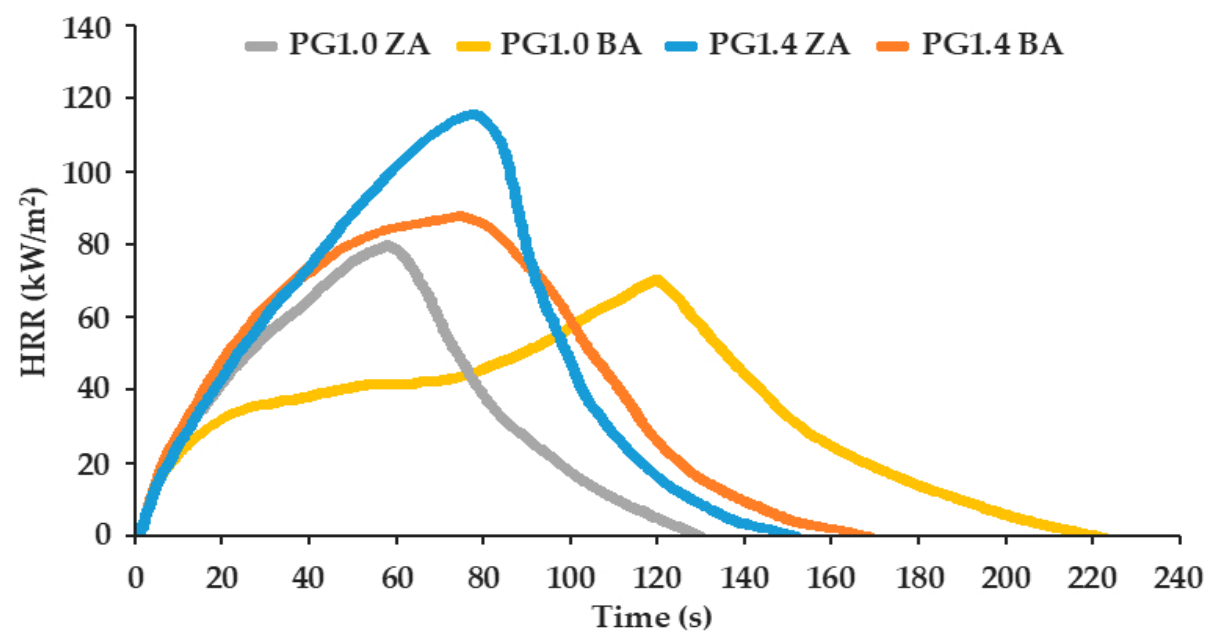

Figure 10. Heat release rate (HRR) as a function of time for RPU/PIR foams.

The foam obtained from a petrochemical polyol, which did not contain a flame retardant (P1.0 BA), was characterized by a lower HRR than other foams, which were obtained from bio-polyol and with or without flame retardant. It should be noted that these foams reached this rate in shorter time (after about $50 \mathrm{~s}$ ), while the P1.0 BA foam ignited quickly but burned slowly. It also released heat slowly, and reached its maximum burning rate after a longer time $(120 \mathrm{~s})$. The P1.4 ZA foam reached the highest value of the HRR, which was $114.8 \mathrm{~kW} / \mathrm{m}^{2}$. The P1.0 BA foam had an HRR value of about $60 \mathrm{~kW} / \mathrm{m}^{2}$. The addition of a flame-retardant compound to the obtained foams also affected the total heat released (Table 5). The reduction of THR was visible after addition of the bio-polyol and the chloro-phosphorus flame retardant into the polyurethane composition. These values were from $23.1 \mathrm{MJ} / \mathrm{m}^{2}$ for the P1.0 BA foam to $9.7 \mathrm{MJ} / \mathrm{m}^{2}$ for the P1.4 ZA foam. The flammability reduction, which can be observed for foams modified by mustard-based polyol and Antiblaze TCMP, was due to the introduction of sulfur heteroatom, as well as chlorine and phosphorus atoms, into the polyurethane. The chain reaction of free radicals formed in the gaseous phase was interrupted during the combustion process. 
This resulted in the dilution of gaseous products and the extinguishment of the flame. In addition, the flame-retardant effect was increased with increasing the sulfur content due to aforementioned synergistic effect. The combined effect of bio-polyol and flame-retardant compound in condensed and gas phases resulted in increased flame retardancy of the obtained RPU/PIR foams.

\subsection{Susceptibility to Biodegradation}

A very important problem of the modern world is the faster and faster increase in the consumption of polymeric materials, and thus the increasing emission of waste. This problem is especially visible in the case of RPU/PIR foams. These materials are much more resistant to degradation due to the presence of isocyanurate rings in their structure. The presence of this group also causes their waste to be very persistent in the environment (the natural decomposition lasts hundreds or thousands of years). RPU/PIR foams waste can be chemically processed, e.g., in a glycolysis process. However, full-valued products cannot be obtained, such as before their synthesis. The obtained glycolysates can only constitute an admixture to formulations of RPU/PIR foams because they frequently affect the deterioration of all performance properties of materials $[5,65,66]$.

Another reason for the high resistance of RPU/PIR foams to environmental factors is the presence of petrochemical raw materials (mainly carbon of petrochemical origin) in their composition. They are much less degradable in the environment than raw materials of plant origin [67]. Therefore, it was examined how the modification of the smallest $(0.1 \mathrm{Eq})$ and the highest $(0.4 \mathrm{Eq})$ content of white mustard seed oil-based bio-polyol would affect the biodegradation process of RPU/PIR foams in soil. For this purpose, the share of individual elements in RPU/PIR foams subjected to the biodegradation process was determined based on literature and experimental data (elemental analysis of raw materials). The obtained results are shown in Table 6.

Table 6. Calculated mass shares of individual elements.

\begin{tabular}{ccccccccccc}
\hline Element & $\mathbf{C}$ & $\mathbf{H}$ & $\mathbf{O}$ & $\mathbf{S i}$ & $\mathbf{N}$ & $\mathbf{S}$ & $\mathbf{P}$ & $\mathbf{C l}$ & $\mathbf{K}$ & $\mathbf{F}$ \\
\hline PG1.0 ZA & 0.599 & 0.057 & 0.168 & 0.005 & 0.059 & 0.000 & 0.012 & 0.041 & 0.002 & 0.058 \\
PG1.1 ZA & 0.6 & 0.059 & 0.164 & 0.005 & 0.058 & 0.002 & 0.012 & 0.041 & 0.002 & 0.058 \\
PG1.4 ZA & 0.603 & 0.063 & 0.153 & 0.005 & 0.056 & 0.007 & 0.012 & 0.041 & 0.002 & 0.058 \\
PG1.0 BA & 0.638 & 0.057 & 0.164 & 0.005 & 0.067 & 0.000 & 0.000 & 0.000 & 0.003 & 0.066 \\
PG1.1 BA & 0.639 & 0.059 & 0.159 & 0.005 & 0.066 & 0.002 & 0.000 & 0.000 & 0.003 & 0.066 \\
PG1.4 BA & 0.643 & 0.065 & 0.146 & 0.005 & 0.064 & 0.008 & 0.000 & 0.000 & 0.003 & 0.066 \\
\hline
\end{tabular}

The results presented in Table 6 showed that elements such as carbon, hydrogen, oxygen, nitrogen, and sulfur underwent fundamental changes in RPU/PIR foams after modification by bio-polyol. The amounts of other elements constituting the additives (e.g., potassium from the trimerization catalyst) did not change because their mass share was always calculated in relation to the current masses of polyol raw materials and polyisocyanate. Although the content of $\mathrm{C}, \mathrm{H}, \mathrm{O}, \mathrm{N}$, was variable in all foams, it was still close to the composition of the reference foam.

Samples prepared in accordance with ISO 17556:2012 were tested into the OxiTop Control S6 apparatus, where the changes in the biochemical oxygen demand in the system $\left(\mathrm{BOD}_{\mathrm{x}}\right)$ were monitored by the respirometric method for 28 days. The results of $\mathrm{BOD}_{\mathrm{x}}$ changes for the tested RPU/PIR foams are shown in Figure 11. 


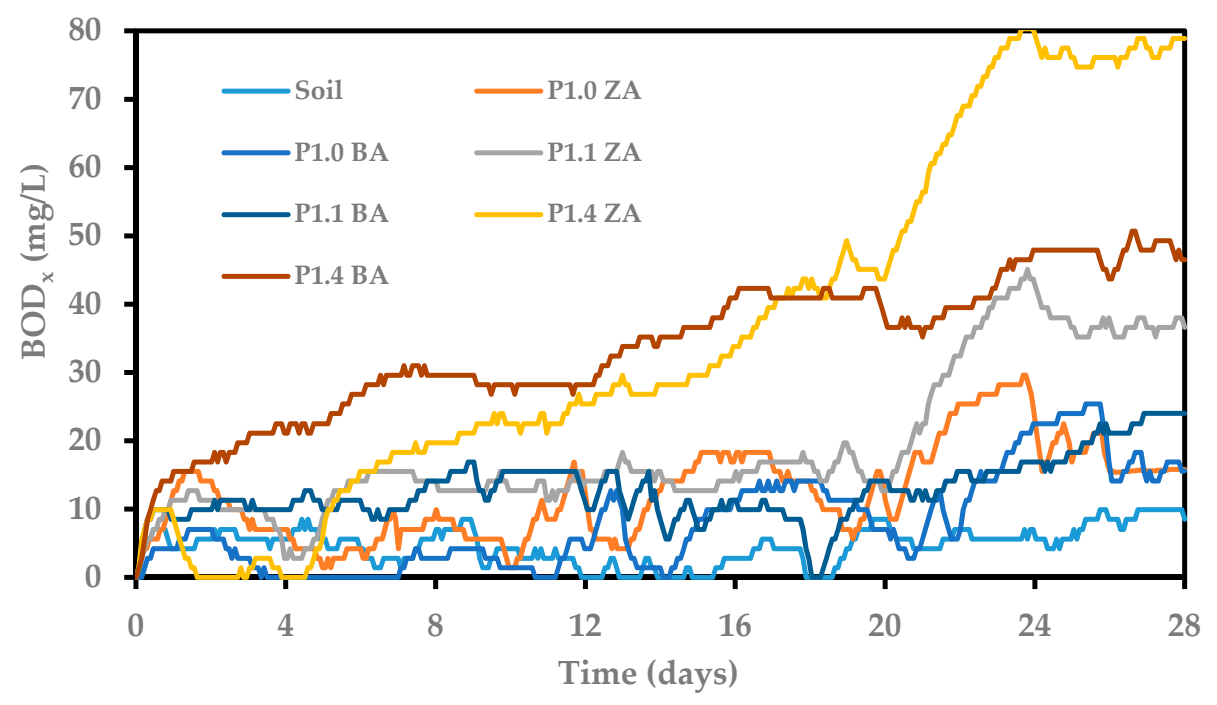

Figure 11. Results of biochemical oxygen demand of RPU/PIR foams during 28 days in soil.

The $\mathrm{BOD}_{28}$ values were calculated from Equation (10) based on the results of measured changes in biochemical oxygen demand (Figure 11). It is necessary to determine the degree of polymer biodegradation $\left(\mathrm{D}_{\mathrm{t}}\right.$ in Equation (11)) after 28 days in soil. Table 7 presents the results of calculated values of $\mathrm{BOD}_{28}$, TOD (calculated on the basis of Equation (12) and the results from Table 6) and the degree of biodegradation of RPU/PIR foams based on white mustard seed oil-based bio-polyol.

Table 7. Results of biodegradability RPU/PIR foams.

\begin{tabular}{ccccccc}
\hline Foam symbol & PG1.0 ZA & PG1.1 ZA & PG1.4 ZA & PG1.0 BA & PG1.1 BA & PG1.4 BA \\
\hline BOD $_{\mathbf{2 8}}(\mathbf{m g} / \mathbf{L})$ & 7.0 & 28.1 & 70.4 & 7.1 & 15.5 & 38.0 \\
TOD $(\mathbf{m g} / \mathbf{L})$ & 87.2 & 86.7 & 95.0 & 90.3 & 94.6 & 97.5 \\
$\mathbf{D}_{\mathbf{t}}(\mathbf{\%})$ & 8.0 & 32.4 & 74.1 & 7.9 & 16.4 & 39.0 \\
\hline
\end{tabular}

An increase in biochemical oxygen demand was observed, along with an increase in the content of bio-polyol in RPU/PIR foams in both series. The highest values of this parameter (e.g., $70.4 \mathrm{mg} / \mathrm{L}$ ) were noted for foams modified with the highest amount of white mustard oil-based bio-polyol. The obtained results of biochemical oxygen demand were several times higher than for reference foams. The degree of polymer biodegradation $\left(D_{t}\right)$ was determined based on the obtained results. Biodegradation degrees for reference foams were $8.0 \%$ (ZA series) and 7.9\% (BA series), respectively, whereas, the $D_{t}$ for foams modified by bio-polyol were from 32.4 to $74.1 \%$ for the ZA series and from 16.4 to $39.0 \%$ for the BA series. The process of biological degradation of RPU/PIR foams was better in foams with a commercial flame retardant than in foams without its participation. An important factor causing the increase of $\mathrm{D}_{\mathrm{t}}$ in modified foams (both in the ZA and BA series) was the presence of a sulfur heteroatom in the polyurethane structure. This element is a so-called biogenic element, meaning that it is necessary for the proper functioning of all living organisms. The literature provides information that the presence of sulfur in soil causes an increase in the development of microorganisms contained in the soil [68]. Thus, the addition of this element in the structure of a compound of natural origin (vegetable oil) favored its release into the biodegradation environment (garden soil), which led to an increase in the overall biodegradation of these materials.

The high biodegradation degree of the polymer is undoubtedly a big advantage of the obtained RPU/PIR foams. In particular, it is much higher for modified foams than for the reference foams. This suggests that the presence of elements, such as carbon, hydrogen, oxygen, nitrogen, or sulfur, introduced in the plant raw materials, can significantly improve the biodegradation ability of rigid foams. However, the scale of the whole measurement should also be noted. To carry out this process, 
the RPU/PIR foam samples were mixed with soil in a mass ratio of 1 to 1500 (200 $\mathrm{mg}$ of foam to $200 \mathrm{~g}$ of dry soil and $100 \mathrm{~g}$ of distilled water). This means that proper preparation of biodegradable material and very large excess of matter constituting the biodegradation environment are required [69].

\section{Conclusions}

The use of bio-polyol based on mustard seed oil in the mixture with petrochemical polyol allowed us to obtain new polyurethane materials with properties similar to or better than commercially available ones. The increase in content of plant-oil based polyol caused a slight increase in technological times. It was also found that the use of bio-polyol had positive influence on the properties of rigid polyurethane-polyisocyanurate foams. RPU/PIR foams obtained based on bio-polyol had a lower apparent density (about $35 \mathrm{~kg} / \mathrm{m}^{3}$ ), lower water absorption (about $1.5-2 \%$ ), and lower thermal conductivity coefficient (about $25 \mathrm{~mW} /(\mathrm{m} \cdot \mathrm{K})$ ) than foams based on petrochemical polyol. Furthermore, the obtained materials were more resistant to aging. The use of polyol, which contain sulfur heteroatoms, significantly reduced the flammability of the obtained polyurethane materials. All foams based on PG1 bio-polyol had LOI above $21 \%$, which classified them as flame-retardant materials. The use of bio-polyols and flame retardant in the formulation allowed the introduction of sulfur and phosphorus compounds into the RPU/PIR foam structure. The addition of these compounds caused a flame-retardant effect through the synergistic interaction between them. Chlorine and bromine containing flame retardants can be eliminated due to this phenomenon because they cause environmental controversy. Therefore, their use in some sectors of the economy (e.g., in electrical engineering) is forbidden. It should be noted that such restrictions have not yet been introduced in civil engineering to which this article referred. The greatest advantage of RPU/PIR foams based on white mustard oil-based polyol and 2,2'-thiodiethanol was its biodegradability in soil. The degree of foam biodegradation of the ZA series with the highest content of bio-polyol was $74.1 \%$ in 28 days. The main disadvantage of these materials was the decrease of compressive strength. However, its final value was within the range of values assumed for this type of polyurethane materials (above $280 \mathrm{kPa}$ ).

The research results presented in this article indicate a very high application potential of bio-polyols based on white mustard seed oil for the production of rigid polyurethane-polyisocyanurate foams dedicated for thermal insulation. The nature-based raw material used in this study is a perfect example of implementation of sustainable development rules in the chemical technology and technology of polymeric materials. The use of renewable materials as a substitute for petrochemical raw materials is currently the leading-edge trend in the polyurethane industry. We can obtain alternative products to conventional materials and take care of the natural environment at the same time.

\section{Patents}

The research results are protected by the Polish Patent No. PL 233221.

Supplementary Materials: The following are available online at http://www.mdpi.com/2073-4360/11/11/1816/s1.

Author Contributions: Conceptualization, M.B.; methodology, M.B. and J.P.-S.; software, M.B.; validation, M.B and J.P.-S.; formal analysis, B.C.; investigation, M.B., J.P.-S. and J.L.; data curation, M.B.; writing-original draft preparation, M.B. and J.P.-S.; visualization, M.B. and J.L.; supervision, B.C.

Funding: This research received no external funding.

Conflicts of Interest: The authors declare no conflict of interest

\section{References}

1. Bukowski, Z. Sustainable Development in the Law System; TNOIK Dom Organiztora: Torun, Poland, 2009. (In Polish)

2. Report of the World Commission on Environment and Development: Our Common Future. 1987. Available online: http://www.un-documents.net/our-common-future.pdf (accessed on 19 September 2019). 
3. Żmihorska-Gotfryd, A. Selected Aspects of Biological Degradation of Polymers; Politechniki Rzeszowskiej: Rzeszów, Poland, 2015. (In Polish)

4. Dobrzyńska, R. The toxicity of products of thermal decomposition and combustion of polyurethane foams used in manufacturing of upholstered furniture. Saf. Fire Tech. 2012, 4, 53-58.

5. Prociak, A.; Rokicki, G.; Ryszkowska, J. Polyurethane Materials; Wydawnictwo Naukowe PWN: Warsaw, Poland, 2014. (In Polish)

6. Septevani, A.A.; Evans, D.A.C.; Chaleat, C.; Martin, D.J.; Annamalai, P.K. A systematic study substituting polyether polyol with palm kernel oil based polyester polyol in rigid polyurethane foam. Ind. Crop. Prod. 2015, 66, 16-26. [CrossRef]

7. Chian, K.S.; Gan, L.H. Development of a rigid polyurethane foam from palm oil. J. Appl. Polym. Sci. 1998, 68, 509-515. [CrossRef]

8. Kurańska, M.; Prociak, A. The influence of rapeseed oil-based polyols on the foaming process of rigid polyurethane foams. Ind. Crop. Prod. 2016, 89, 182-187. [CrossRef]

9. Paciorek-Sadowska, J.; Czupryński, B.; Borowicz, M.; Liszkowska, J. New polyurethane materials containing biofiller. Polimery 2015, 9, 586-591. [CrossRef]

10. Miao, S.; Sun, L.; Wang, P.; Liu, R.; Su, Z.; Zhang, S. Soybean oil-based polyurethane networks as candidate biomaterials: Synthesis and biocompability. Eur. J. Lipid Sci. Technol. 2012, 114, 1165-1174. [CrossRef]

11. Miao, S.; Zhang, S.; Su, Z.; Wang, P. Synthesis of bio-based polyurethanes from epoxidized soybean oil and isopropanolamine. J. Appl. Polym. Sci. 2013, 10, 1929-1936. [CrossRef]

12. Miao, S.; Callow, N.; Wang, P.; Liu, Y.; Su, Z.; Zhang, S. Soybean oil-based polyurethane networks: Shape-memory effects and Surface morphologies. J. Am. Oil Chem. Soc. 2013, 90, 1415-1421. [CrossRef]

13. Veronese, V.B.; Menger, R.K.; de, C.; Forte, M.M.; Petzhold, C.L. Rigid polyurethane foam based on vegetable oil. J. Appl. Polym. Sci. 2011, 120, 530-537. [CrossRef]

14. Dhaliwal, G.S.; Anandan, S.; Chandrashekhara, K.; Lees, J.; Nam, P. Development and characterization of polyurethane foams with substitution of polyether polyol with soy-based polyol. Eur. Polym. J. 2018, 107, 105-117. [CrossRef]

15. Dhaliwal, G.S.; Anandan, S.; Chandrashekhara, K.; Dudenhoeffer, N.; Nam, P. Fabrication and Testing of Soy-Based Polyurethane Foam for Insulation and Structural Applications. J. Polym. Environ. 2019, 27, 1897-1907. [CrossRef]

16. Prociak, A.; Kurańska, M.; Cabulis, U.; Kirpluks, M. Rapeseed oil as main component in synthesis of bio-polyurethane-polyisocyanurate porous materials modified with carbon fibers. Polym. Test. 2017, 59, 478-486. [CrossRef]

17. Malewska, E.; Prociak, A. The effect of nanosilica filler on the foaming process and properties of flexible polyurethane foams obtained with rapeseed oil-based polyol. Polimery 2015, 60, 472-479. [CrossRef]

18. Malewska, E.; Bak, S.; Kurańska, M.; Prociak, A. The effect of various rapeseed oil-based polyols on selected properties of flexible polyurethane foams. Polimery 2016, 61, 799-806. [CrossRef]

19. Badri, K.H.; Redhwan, A.M. Effect of Phosphite Loading on the Mechanical and Fire Properties of Palm-Based Polyurethane. Sains Malays. 2010, 39, 769-774.

20. Badri, K.H. Biobased polyurethane from palm kernel oil-based polyol. In Polyurethane; Zafar, F., Sharmin, E., Eds.; InTechOpen: Rijeka, Croatia, 2012; pp. 447-470. [CrossRef]

21. Su'ait, M.S.; Ahmad, A.; Badri, K.H.; Mohamed, N.S.; Rahman, M.Y.A.; Ananza Ricardo, C.L.; Scardi, P. The potential of polyurethane bio-based solid polymer electrolyte for photoelectrochemical cell application. Int. J. Hydrog. Energy 2014, 39, 3005-3017. [CrossRef]

22. Adnan, S.; Tuan Noor, M.T.I.; Ain, N.H.; Devi, K.P.P.; Mohd, N.S.; Kian, Y.S.; Idris, Z.B.; Campara, I.; Schiffman, C.M.; Pietrzyk, K.; et al. Impact of the hard-segment concentration on highly resilient polyurethane foams based on palm olein polyol. J. Appl. Polym. Sci. 2017, 134, 45440. [CrossRef]

23. Paciorek-Sadowska, J.; Borowicz, M.; Czupryński, B.; Liszkowska, J. The Method of Obtaining Polyol Raw Material for the Synthesis of Rigid Polyurethane-Polyisocyanurate Foams and the Method of Synthesis of Rigid Polyurethane-Polyisocyanurate Foams. Poland Patent Application No. 233221, 17 September 2017. (In Polish). 
24. Paciorek-Sadowska, J.; Borowicz, M.; Czupryński, B.; Liszkowska, J. New bio-polyol based on white mustard seed (Sinapis alba) as an alternative raw material for the polyurethane industry. Polimery 2018, 63, 38-43. [CrossRef]

25. Paciorek-Sadowska, J.; Borowicz, M.; Czupryński, B.; Isbrandt, M. Effect of evening primrose oil-based polyol on the properties of rigid polyurethane-polyisocyanurate foams for thermal insulation. Polymers 2018, 10, 1334. [CrossRef]

26. Paciorek-Sadowska, J.; Borowicz, M.; Czupryński, B.; Tomaszewska, E.; Liszkowska, J. New bio-polyol based on white mustard seed oil for rigid PUR-PIR foams. Pol. J. Chem. Tech. 2018, 20, 24-31. [CrossRef]

27. ASTM International. Standard Practice for Polyurethane Raw Materials: Polyurethane Foam Cup Test; ASTM Standard D7487-13e1, 2008; ASTM International: West Conshohocken, PA, USA, 2016.

28. ISO Standard, no. 17556:2012. Plastics-Determination of the Ultimate Aerobic Biodegradability of Plastic Materials in Soil by Measuring the Oxygen Demand in a Respirometer or the Amount of Carbon Dioxide Evolved; International Organization for Standardization: Geneva, Switzerland, 2012.

29. Li, Y.; Luo, X.; Hu, S. (Eds.) Polyols and Polyurethanes from Vegetable Oils and Their Derivatives. In Bio-Based Polyols and Polyurethanes; Springer: New York, NY, USA, 2015; Volume 1, Chapter 2; pp. 15-43.

30. Beltran, A.A.; Boyaca, L.A. Production of rigid polyurethane foams from soy-based polyols. Lat. Am. Appl. Res. 2011, 41, 75-80.

31. Prociak, A.; Kurańska, M.; Malewska, E. Porous polyurethane plastics synthetized using bio-polyols from renewable raw materials. Polimery 2017, 62, 353-363. [CrossRef]

32. Paciorek-Sadowska, J.; Borowicz, M.; Czupryński, B.; Liszkowska, J. Composites of rigid polyurethane-polyisocyanurate foams with oak bark. Polimery 2017, 62, 666-672. [CrossRef]

33. Paciorek-Sadowska, J.; Borowicz, M.; Czupryński, B.; Liszkowska, J.; Tomaszewska, E. Application of halloysite as filler in the production of rigid PUR-PIR foams. Polimery 2018, 63, 185-190. [CrossRef]

34. Kurańska, M.; Prociak, A. Bio-Based Polyurethane Foams for Heat-Insulating Applications. In Nano and Biotech Based Materials for Energy Building Efficiency; Pacheco, T., Buratti, F.C., Kalaiselvam, S., Granqvist, C., Ivanov, V., Eds.; Springer Nature Switzerland AG: Basel, Switzerland, 2016; Volume 1, pp. 357-374.

35. Chuang, W.; Su, Y.; Huang, Y.; Sheen, Y.; Chiang, C. Bio-polyol Composition and Bio-Polyurethane Foam. U.S. Patent Application No. 20170158802, 8 June 2017.

36. Lorusso, C.; Vergaro, V.; Conciauro, F.; Ciccarella, G.; Congedo, P.M. Thermal and mechanical performance of rigid polyurethane foam added with commercial nanoparticles. Nanomater. Nanotechnol. 2017, 7, 1-9. [CrossRef]

37. PIANEX Co. Catalogue of Products. Parameters of PUR-PIR Foams. Available online: http://www.pianex.pl/ pur-pir-parametry, 48.html (accessed on 19 September 2019).

38. Stirna, U.; Sevastyanova, I.; Misane, M.; Cabulis, U.; Beverte, I. Structure and properties of polyurethane foams obtained from rapeseed oil polyols. Proc. Estonian Acad. Sci. Chem. 2006, 55, 101-110.

39. Murayama, S.; Fukuda, K.; Kimura, T.; Sasahara, T. Water-blown Polyurethane Rigid Foam Modified with Maleate. J. Cell. Plast. 2005, 41, 373-387. [CrossRef]

40. Sripathy, M.; Sharma, K.V. Flammability and Moisture absorption test of rigid polyurethane foam. Int. J. Sci. Eng. Res. 2013, 2, 1-8.

41. Paciorek-Sadowska, J. Synthesis of rigid polyurethane-polyisocyanurate foams. In Studies on Influence of Derivatives of $N, N^{\prime}$-di(methyleneoxy-hydoxyalkyl)urea and Boric Acid on Properties of Rigid Polyurethane-Polyisocyanurate Foams; WU Uniwersytetu Kazimierza Wielkiego: Bydgoszcz, Poland, 2011; Volume 1, pp. 93-124. (In Polish)

42. Paciorek-Sadowska, J.; Borowicz, M.; Isbrandt, M. New Poly(lactide-urethane-isocyanurate) Foams Based on Bio-Polylactide Waste. Polymers 2019, 11, 481. [CrossRef]

43. Radziszewska-Zielina, E. Comparative analysis of parameters of thermal insulation materials using as an external insulation of wall. Przeglad Budowlany 2009, 4, 32-37. (In Polish)

44. Yarahmadi, N.; Vega, A.; Jakubowicz, I. Accelerated ageing and degradation characteristics of rigid polyurethane foam. J. Polym. Degrad. Stab. 2017, 138, 192-200. [CrossRef]

45. Xie, J.; Qi, J.; Hse, C.; Shupe, T.F. Effect of lignin derivatives in the bio-polyols from microwave liquefied bamboo on the properties of polyurethane foams. BioResources 2014, 9, 578-588. [CrossRef] 
46. Zhang, C.; Kessler, M.R. Bio-based Polyurethane Foam Made from Compatible Blends of Vegetable-Oil-based Polyol and Petroleum-based Polyol. ACS Sustain. Chem. Eng. 2015, 3, 743-749. [CrossRef]

47. Hejna, A.; Kirpluks, M.; Kosmela, P.; Cabulis, U.; Haponiuk, J.; Piszczyk, Ł. The influence of crude glycerol and castor oil-based polyol on the structure and performance of rigid polyurethane-polyisocyanurate foams. Ind. Crop. Prod. 2017, 95, 113-125. [CrossRef]

48. Kang, J.W.; Kim, J.M.; Kim, M.S.; Kim, Y.H.; Kim, W.N.; Jang, W.; Shin, D.S. Effects of nucleating agents on the morphological, mechanical and thermal insulating properties of rigid polyurethane foams. Macromol. Res. 2009, 17, 856-862. [CrossRef]

49. Dolomanova, V.; Jens, C.M.R.; Jensen, L.R.; Pyrz, R.; Timmons, A.B. Mechanical properties and morphology of nano-reinforced rigid PU foam. J. Cell. Plast. 2011, 47, 81-93. [CrossRef]

50. Niyogi, D.; Kumar, R.; Gandhi, K.S. Water blown free rise polyurethane foams. Polym. Eng. Sci. 1999, 39, 199-209. [CrossRef]

51. Zhang, H.; Fang, W.; Li, Y.; Tao, W. Experimental study of the thermal conductivity of polyurethane foams. J. Appl. Therm. Eng. 2016, 115, 528-538. [CrossRef]

52. Kuhn, J.; Ebert, H.P.; Arduini-Shuster, M.C.; Buttner, D.; Fricke, J. Thermal transport in polystyrene and polyurethane foam insulations. Int. J. Heat Mass Transf. 1992, 35, 1795-1801. [CrossRef]

53. Kurańska, M.; Cabulis, U.; Auguścik, M.; Prociak, A.; Ryszkowska, J.; Kirpluks, M. Bio-based polyurethane-polyisocyanurate composites with an intumescent flame retardant. Polym. Deg. Stab. 2016, 127, 11-19. [CrossRef]

54. Modesti, M.; Lorenzetti, A.; Simioni, F.; Checchin, M. Influence of different flame retardants on fire behaviour of modified PIR/PUR polymers. Polym. Deg. Stab. 2001, 74, 475-479. [CrossRef]

55. Sankowska, M.; Gajek, A.; Celiński, M. Analysis of toxic products of thermal decomposition and combustion of substrates used in the synthesis of polyurethanes. Przem. Chem. 2016, 95, 1237-1242. [CrossRef]

56. Chen, M.J.; Wang, X.; Tao, M.C.; Liu, X.Y.; Liu, Z.G.; Zhang, Y.; Zhao, C.S.; Wang, J.S. Full substitution of petroleum-based polyols by phosphorus-containing soy-based polyols for fabricating highly flame-retardant polyisocyanurate foams. Polym. Deg. Stab. 2018, 154, 312-322. [CrossRef]

57. Janowska, G.; Rybiński, P.; Krauze, S. The effect of the curing agent type on the flammability of butadiene-acrylonitrile rubbers. Polimery 2006, 51, 735-741. [CrossRef]

58. Rasmussen, C.L.; Glarborg, P.; Marshall, P. Mechanisms of radical removal by $\mathrm{SO}_{2}$. Peoc. Combust. Inst. 2007, 31, 339-347. [CrossRef]

59. Paciorek-Sadowska, J. Polyol containing boron atoms as a compound which reduces flammability of rigid polyurethane-polyisocyanurate foam. In Aspects of Polyurethanes; Yilmaz, F., Ed.; InTech: Rijeka, Croatia, 2017; pp. 111-130. [CrossRef]

60. Chmiel, E.; Lubczak, J. Synthesis of oligoetherols from mixtures of melamine and boric acid and polyurethane foams formed from these oligoetherols. Polym. Bull. 2019, 76, 2253-2275. [CrossRef]

61. Chmiel, E.; Oliwa, R.; Lubczak, J. Boron-containing non-flammable polyurethane foams. Polym. Plast. Technol. Eng. 2019, 58, 394-404. [CrossRef]

62. Paciorek-Sadowska, J.; Borowicz, M.; Isbrandt, M.; Czupryński, B.; Apiecionek, Ł. The Use of Waste from the Production of Rapeseed Oil for Obtaining of New Polyurethane Composites. Polymers 2019, 11, 1431. [CrossRef]

63. Bhoyate, S.; Ionescu, M.; Kahol, P.K.; Gupta, R.K. Sustainable flame-retardant polyurethanes using renewable resources. Ind. Crop. Prod. 2018, 123, 480-488. [CrossRef]

64. Bhoyate, S.; Ionescu, M.; Kahol, P.K.; Chen, J.; Mishra, S.R.; Gupta, R.K. Highly flame-retardant polyurethane foam based on reactive phosphorus polyol and limonene-based polyol. J. Appl. Polym. Sci. 2018, 135, 46224. [CrossRef]

65. Czupryński, B. Issues From Chemistry and Technology of Polyurethanes; Wydawnictwo Akademii Bydgoskiej: Bydgoszcz, Poland, 2004.

66. Paciorek-Sadowska, J. Chemical recycling of rigid PUR-PIR foams with boronitrile flame retardant. Inż. Ap. Chem. 2010, 49, 93-94. (In Polish)

67. Das, N.; Chandran, P. Microbial Degradation of Petroleum Hydrocarbon Contaminants: An Overview. Biotechnol. Res. Int. 2011, 2011, 941810. [CrossRef] [PubMed] 
68. Klotz, M.G.; Bryant, D.A.; Hanson, T.E. The microbial sulfur cycle. Front. Microbiol. 2011, 2, 241. [CrossRef] [PubMed]

69. Borowicz, M. Synthesis and Application of New Bio-Polyols Aased on Vegetable Raw Materials for the Production of Bio-Composites in the Form of Rigid Polyurethane-Polyisocyanurate Foams. Ph.D. Thesis, West Pomeranian University of Technology, Szczecin, Poland, 2019.

(C) 2019 by the authors. Licensee MDPI, Basel, Switzerland. This article is an open access article distributed under the terms and conditions of the Creative Commons Attribution (CC BY) license (http://creativecommons.org/licenses/by/4.0/). 